\title{
Contingent Capital, Tail Risk, and Debt-Induced Collapse
}

\author{
Nan Chen*, Paul Glasserman† Behzad Nouri ${ }^{\ddagger}$ and Markus Pelger ${ }^{\S}$
}

September 2013

\begin{abstract}
Contingent capital in the form of debt that converts to equity as a bank approaches financial distress offers a potential solution to the problem of banks that are too big to fail. This paper studies the design of contingent convertible bonds and their incentive effects in a structural model with endogenous default, debt rollover, and tail risk in the form of downward jumps in asset value. We show that once a firm issues contingent convertibles, the shareholders' optimal bankruptcy boundary can be at one of two levels: a lower level with a lower default risk or a higher level at which default precedes conversion. An increase in the firm's total debt load can move the firm from the first regime to the second, a phenomenon we call debt-induced collapse because it is accompanied by a sharp drop in equity value. We show that setting the contractual trigger for conversion sufficiently high avoids this hazard. With this condition in place, we investigate the effect of contingent capital and debt maturity on optimal capital structure, debt overhang, and asset substitution. We also calibrate the model to past data on the largest U.S. bank holding companies to see what impact contingent convertible debt might have had under the conditions of the financial crisis.
\end{abstract}

Keywords: Contingent convertible debt, bail-in debt, capital structure, too big to fail

JEL Classification Codes: G12, G13, G32

\section{Introduction}

The problem of banks that are too big to fail plays out as an unwillingness on the part of governments to impose losses on bank creditors for fear of the disruptive consequences to the financial system and the broader economy. Higher capital requirements and restrictions on business practices may reduce the likelihood of a bank becoming insolvent, but they do not commit the regulators, managers or investors to a different course of action conditional on a bank approaching insolvency.

\footnotetext{
* Chinese University of Hong Kong, nchen@se.cuhk.edu.hk

${ }^{\dagger}$ Columbia University, pg20@columbia.edu

${ }^{\ddagger}$ Columbia University, bn2164@columbia.edu

§University of California, Berkeley, markus.pelger@berkeley.edu
} 
Contingent capital addresses this problem through a contractual commitment to have bond holders share some of a bank's downside risk without triggering failure. Contingent convertibles (CoCos) and bail-in debt are the two main examples of contingent capital. Both are debt that convert to equity under adverse conditions. CoCos provide "going concern" contingent capital, meaning that they are designed to convert well before a bank would otherwise default. Bailin debt is "gone-concern" contingent capital and converts when the bank is no longer viable, wiping out the original shareholders and transferring ownership to the bailed-in creditors.

These instruments are increasingly important elements of reforms to enhance financial stability. The most prominent examples to date are major issuances by Lloyds Banking Group, Credit Suisse, and BBVA. Rabobank, UBS, and Barclays have issued alternative structures in which debt is automatically written down rather than converted. The Swiss banking regulator has increased capital requirements for Swiss banks to $19 \%$ of risk-weighted assets, of which $9 \%$ can take the form of CoCos. The European Commission's proposed resolution framework relies on bail-in debt as one of its primary tools. In the U.S., bail-in is central to the implementation of the FDIC's authority to resolve large complex financial institutions granted by the Dodd-Frank act.

The logic of contingent capital is compelling. Raising new equity from private investors is particularly difficult for a bank nearing financial distress, which strengthens arguments for government support once a crisis hits; contingent capital solves this problem by committing creditors to provide equity through conversion of their claims. Nevertheless, the relative complexity of these instruments has raised some questions about whether they can be designed to function as expected and whether they might have unintended consequences.

The goal of this paper is to analyze the design of contingent capital and to investigate the incentives these instruments create for shareholders. This work makes several contributions. First, our analysis reveals a new phenomenon we call debt-induced collapse. With CoCos on its balance sheet, a firm operates in one of two regimes: one in which the CoCos function as intended or another in which the equity holders optimally declare bankruptcy before conversion, effectively reducing the CoCos to straight debt. A transition from the first regime to the second is precipitated by an increase in the firm's debt load, and its consequences include a sharp increase in the firm's default probability and a drop in the value of its equity. This is the sense in which debt induces a collapse. We show that this hazard is avoided by setting the trigger for conversion at a sufficiently high level.

Once debt-induced collapse is precluded, we can investigate the incentive effects of CoCos - effects that would be lost in the alternative regime in which CoCos degenerate to straight 
debt. We characterize the firm's optimal capital structure and how it responds to a regulatory debt limit. We investigate how the value of equity responds to various changes in capital structure and find, perhaps surprisingly, that equity holders often have a positive incentive to issue CoCos. We also find that CoCos can be effective in mitigating the problem of debt overhang - the reluctance of equity holders to inject additional capital into an ailing firm when most of the resulting increase in firm value is captured by debt holders. CoCos can create a strong positive incentive for shareholders to invest additional equity to stave off conversion. We also examine how CoCos affect the sensitivity of equity value to the riskiness of the firm's assets. This sensitivity is always positive in simple models, creating an incentive for asset substitution by shareholders once they have issued debt. We will see that this is not necessarily the case in a richer setting in which new debt is issued as old debt matures.

We develop our analysis in a structural model of the type introduced in Leland [21] and Leland and Toft [22], as extended by Chen and Kou [7] to include jumps. The key state variable is the value of the firm's underlying assets, and equity and debt values are derived as functions of this state variable. We assume that CoCo conversion is also triggered by this state variable through a decline in the value of the firm's assets. The model has three particularly important features. First, default is endogeneous and results from the optimal behavior of equity holders. This feature is essential to the analysis of incentive effects and to the emergence of the two default regimes described above. Second, the firm's debt has finite maturity and must be rolled over as it matures. This, too, is crucial in capturing incentive effects. In a classical single-period model of the type in Merton [25], all the benefits of reducing default risk accrue to bond holders - equity holders always prefer riskier assets and are always deterred from further investment by the problem of debt overhang. But in a model with debt rollover, reducing default risk allows the firm to issue debt at a higher market price, and part of this increase in firm value is captured by equity holders, changing their incentives. This feature also allows us to investigate how debt maturity interacts with the efficacy of CoCos. Finally, jumps are also essential to understanding incentive effects. Downward jumps generate a higher asset yield (in the form of an increase in the risk-neutral drift) but expose the firm to tail risk. CoCos can increase equity holders' incentive to take on tail risk because equity holders would prefer a dilutive conversion at a low asset value over one at a high asset value. For the same reason, CoCos are more effective in mitigating debt overhang when asset value is subject to downward jumps.

After demonstrating these implications through a mix of theoretical and numerical results, we calibrate the model to data on the largest U.S. bank holding companies for the period 20042011. Some of the comparative statics in our numerical examples depend on parameters values, 
so the purpose of the calibration is to investigate the model's implications at parameter values representative of the large financial institutions that would be the main candidates for CoCo issuance. We calculate the model-implied increase in loss absorption that would have resulted from replacing $10 \%$ of each firm's debt with CoCos, estimate which firm's would have triggered conversion and when, and compare the impact on debt overhang costs at three dates during the financial crisis. Overall, this counterfactual exploration suggests that CoCos would have had a beneficial effect, had they been issued in advance of the crisis.

As noted above, our model defines the trigger for conversion through the level of the firm's assets. This modeling device, though natural from the perspective of a structural model of the firm, is an idealization because asset value is not directly observable, particularly in continuous time. All actual issuances to date rely on regulatory accounting-based triggers like a Tier 1 capital ratio. We take the view that an accounting-based measure is a practical compromise and serves to approximate the "true" underlying asset value. Viewed from this perspective, our model does not account for the approximation error but is nevertheless aligned with the objectives of the regulatory triggers in current use.

A structural model of the firm can provide valuable insight, even as a radical simplification of reality. The specific case of a bank has special features that require comment. Most of a bank's debt is in the form of deposits with no fixed maturity; our setting can be interpreted as assigning a random, exponentially distributed maturity to debt. More importantly, whereas debt issued by an industrial firm is used to finance projects, the creation of demand deposits is a core element of a bank's business. Depositors value the liquidity of deposits and in effect earn a convenience yield from these liabilities beyond the interest paid by the bank. This is analogous to the effect of tax deductibility of interest expenses, where the coupon earned by bond holders is greater than the after-tax coupon paid by the issuer. The value of liquidity created by the bank could thus be modeled the way we treat the debt tax shield, though to keep the model simple we do not do this explicitly. Similar comments apply to subsidized deposit insurance, which is incorporated in an extension of our basic model discussed in the appendix.

Albul, Jaffee, and Tchistyi [1] also develop a structural model for the analysis of contingent capital; their model has neither jumps nor debt rollover (they consider only infinite maturity debt), and their analysis and conclusions are quite different from ours. Pennacchi's [30] model includes jumps and instantaneous maturity debt; he studies the model through simulation, taking default as exogenous, and thus does not investigate the structure of shareholders' optimal default. Hilscher and Raviv [16] and Himmelberg and Tsyplakov [17] investigate other aspects of contingent capital in rather different models. All of these models use asset-level triggers. Koziol 
and Lawrenz [20] use an earnings trigger; our model also admits this interpretation because we take earnings to be proportional to asset value. Glasserman and Nouri [12] jointly model capital ratios based on accounting and asset values; they value debt that converts progressively, rather than all at once, as a capital ratio deteriorates. None of the previous literature combines the key features of our analysis - endogenous default, debt rollover, jumps, and analytical tractability - nor does previous work identify the phenomenon of debt-induced collapse.

Much of the current interest in contingent capital stems from Flannery [10]. Flannery [10] proposed reverse convertible debentures (called contingent capital certificates in Flannery [11]) that would convert from debt to equity based on a market trigger - a bank's stock price rather than an accounting measure. Sundaresan and Wang [33] raise conceptual concerns about market-based triggers, and Glasserman and Nouri [13] show that these issues are largely resolved if the market trigger is sufficiently liquid to be described by a continuous-time model. Several authors have proposed various types of combined triggers or alternative security designs; these include Bolton and Samama [3], Calomiris and Herring [4], Duffie [9], Madan and Schoutens [23], McDonald [24], Pennacchi, Vermaelen, and Wolf [31], and Squam Lake Working Group [32]; see Pazarbasioglu et al. [29] for an overview.

The rest of this paper is organized as follows. Section 2 details the structural model and derives values for the firm's liabilities. Section 3 characterizes the endogenous default barrier and includes our main theoretical results describing debt-induced collapse. Section 4 presents implications of these results for optimal capital structure and regulation. Sections $5-7$ investigate the impact of debt rollover and incentive effects on debt overhang and asset substitution. Section 8 presents the calibration to bank data. Technical details are deferred to an appendix.

\section{The Model}

\subsection{Firm Asset Value}

Much as in Leland [21], Leland and Toft [22], and Goldstein, Ju, and Leland [14], consider a firm generating cash through its investments and operations continuously at rate $\left\{\delta_{t}, t \geq 0\right\}$. This income flow is exposed to both diffusive and jump risk, with dynamics given by

$$
\frac{d \delta_{t}}{\delta_{t-}}=\tilde{\mu} d t+\tilde{\sigma} d \tilde{W}_{t}+d\left(\sum_{i=1}^{\tilde{N}_{t}}\left(\tilde{Y}_{i}-1\right)\right) .
$$

Here, $\tilde{\mu}$ and $\tilde{\sigma}$ are constants, $\left\{\tilde{W}_{t}, t \geq 0\right\}$ is a standard Brownian motion, and we write $\delta_{t-}$ to indicate the value of $\delta$ just prior to a possible jump at time $t$. Jumps are driven by a Poisson process $\left\{\tilde{N}_{t}, t \geq 0\right\}$ with intensity $\tilde{\lambda}$. The jump sizes $\left\{\tilde{Y}_{i}, i=1,2, \ldots\right\}, \tilde{N}$, and $\tilde{W}$ are all 
independent of each other. Since we are mainly concerned with the impact of downside shocks

to the firm's business, we assume that the $\tilde{Y}_{i}$ are all less than 1 . The common distribution of the $\tilde{Y}_{i}$ is set by positing $\tilde{Z}:=-\log (\tilde{Y})$, for tractability, to have an exponential distribution, $f_{\tilde{Z}}(z)=\tilde{\eta} \exp (-\tilde{\eta} z), z \geq 0$, for some $\tilde{\eta}>0$. We assume a constant risk-free interest rate $r$.

In a rational expectations framework with a representative agent having HARA utility, the equilibrium price of any claim on the future income of the firm can be shown to be the expectation of the discounted payoff of the claim under a "risk-neutral" probability measure Q; see Naik and Lee [28] and Kou [18] for justification of this assertion in the jump-diffusion setting. The value of the firm's assets is the present value of the future cash flows they generate,

$$
V_{t}=\mathbb{E}^{\mathbb{Q}}\left[\int_{t}^{\infty} e^{-r(u-t)} \delta_{u} d u \mid \delta_{t}\right]
$$

for all $t \geq 0$. Following Naik and Lee [28] and Kou [18], we can easily establish that $\delta:=V_{t} / \delta_{t}$ is a constant and $V_{t}$ evolves as a jump-diffusion process

$$
\frac{d V_{t}}{V_{t-}}=\left(r-\delta+\frac{\lambda}{1+\eta}\right) d t+\sigma d W_{t}+d\left(\sum_{i=1}^{N_{t}}\left(Y_{i}-1\right)\right),
$$

Under $\mathbb{Q},\left\{W_{t}\right\}$ in $(2.2)$ is a standard Brownian motion and $\left\{N_{t}\right\}$ is a Poisson processes with intensity $\lambda$. The distribution of the jump size $Y_{i}$ has the same form as before, but now with parameter $\eta$. Kou [18] gives explicit expressions for the parameters in (2.2) in terms of the parameters in (2.1). We will value pieces of the firm's capital structure as contingent claims on the asset value process $V$, taking expectations under $\mathbb{Q}$ and using the dynamics in (2.2).

\subsection{The Capital Structure and Endogenous Default}

The firm finances its assets through straight debt, contingent convertible debt (CoCos), and equity. We detail these in order of seniority.

\subsubsection{Straight Debt}

We use the approach of Leland and Toft [22] to model the firm's senior debt. The firm continuously issues straight debt with par value $p_{1} d t$ in $(t, t+d t)$. The maturity of newly issued debt is exponentially distributed with mean $1 / m$; that is, a portion $m \exp (-m s) d s$ of the total amount $p_{1} d t$ matures during the time interval $(t+s, t+s+d s)$, for each $s \geq 0$. The debt pays a continuous coupon at rate $c_{1}$ per unit of par value. In the case of bank deposits with no stated term, the maturity profile reflects the distribution of time until depositors withdraw 
their funds. ${ }^{1}$

The exponential maturity profile and the constant issuance rate keep the total par value of debt outstanding constant at

$$
P_{1}=\int_{t}^{\infty}\left(\int_{-\infty}^{t} p_{1} m e^{-m(s-u)} d u\right) d s=\frac{p_{1}}{m} .
$$

Thus, the firm continuously settles and reissues debt at a fixed rate. This debt rollover will be important to our analysis through its effect on incentives for equity holders.

\subsubsection{Contingent Convertibles}

We use the same basic framework to model the issuance and maturity of CoCos as we use for straight debt. In both cases, we would retain tractability if we replaced the assumption of an exponential maturity profile with consols, but we would then lose the effect of debt rollover. We denote by $P_{2}$ the par value of CoCos outstanding, which remains constant prior to conversion or default and pays a continuous coupon at rate $c_{2}$. The mean maturity is assumed to be the same as for the straight debt, $1 / m$, and new debt is issued at rate $p_{2}=m P_{2}$.

Conversion of CoCos from debt to equity is triggered when the value of the firm's assets falls below an exogenously specified threshold $V_{c}$. Thus, conversion occurs at

$$
\tau_{c}=\inf \left\{t \geq 0: V_{t} \leq V_{c}\right\},
$$

and we assume the trigger $V_{c}$ is lower than the initial asset level $V_{0}$. (Because earnings $\delta V_{t}$ are proportional to asset value, the trigger could equivalently be based on earnings, as posited in Koziol and Lawrenz [20].) At the instant of conversion, the CoCo liability is erased and CoCo investors receive $\Delta$ shares of the firm's equity for every dollar of principal, for a total of $\Delta P_{2}$ shares. We normalize the number of shares to 1 prior to conversion. Thus, following conversion, the CoCo investors own a fraction $\Delta P_{2} /\left(1+\Delta P_{2}\right)$ of the firm. In the bail-in case, $\Delta=\infty$, so the original shareholders are wiped out and the converted investors take control of the firm. We think of the parameters $\left(V_{c}, \Delta\right)$ as part of the terms of the convertible debt. ${ }^{2}$

\subsubsection{Endogenous Default}

The firm has two types of cash inflows and two types of cash outflows. The inflows are the income stream $\delta_{t} d t=\delta V_{t} d t$ and the proceeds from new bond issuance $b_{t} d t$, where $b_{t}$ is the total

\footnotetext{
${ }^{1}$ As discussed in the introduction, the liquidity value of bank deposits can be viewed as a benefit to depositors beyond the interest expense incurred by the bank and can thus be modeled in the same was as the tax benefit of debt. We introduce the tax shield in Section 2.2.3 and touch on deposit insurance in Appendix B.

${ }^{2}$ We do not distinguish between contractual and statutory conversion. Under the former, conversion is an explicit contractual feature of the debt. The statutory case refers to conversion imposed on otherwise standard debt at the discretion of a regulator granted explicit legal authority to force such a conversion.
} 
market value of bonds issued at time $t$. The cash outflows are the after-tax coupon payments and the principal due $\left(p_{1}+p_{2}\right) d t$ on maturing debt. ${ }^{3}$ The firm has a marginal tax rate of $\kappa$, and we assume that interest payments on straight debt are tax-deductible. Thus, the after-tax coupon payment rate is given by $A_{t}=(1-\kappa)\left(c_{1} P_{1}+c_{2} P_{2}\right)$ or $A_{t}=(1-\kappa) c_{1} P_{1}+c_{2} P_{2}$, depending on whether or not coupon payments on CoCos are also tax deductible.

Let $\bar{p}$ denote the total rate of issuance (and retirement) of par value of debt, just as $b_{t}$ denotes the total rate of issuance measured at market value. We have $\bar{p}=p_{1}+p_{2}$ prior to conversion of any CoCos and $\bar{p}=p_{1}$ after conversion. Whenever

$$
b_{t}+\delta V_{t}>A_{t}+\bar{p}
$$

the firm has a net inflow of cash, which is distributed to equity holders as a dividend flow. When the inequality is reversed, the firm faces a cash shortfall. The equity holders then face a choice between making further investments in the firm - in which case they invest just enough to make up the shortfall - or abandoning the firm and declaring bankruptcy. Bankruptcy then occurs at the first time the asset level is at or below $V_{b}^{*}$, with $V_{b}^{*}$ chosen optimally by the equity holders. In fact, it would be more accurate to say that $V_{b}^{*}$ is determined simultaneously with $b_{t}$, because the market value of debt depends on the timing of default, just as the firm's ability to raise cash through new debt influences the timing of default.

The equity holders choose a bankruptcy policy to maximize the value of equity. To be feasible, a policy must be consistent with limited liability, meaning that it ensures that equity value remains positive prior to default. This formulation is standard and follows Leland [21] and Leland and Toft [22] and, in the jump-diffusion case, Chen and Kou [7].

However, the presence of CoCos creates a distinctive new feature, driven by whether default occurs before or after conversion. Depending on the parameters of the model, the equity holders may find either choice to be optimal. If they choose to default before conversion, then the CoCos effectively degenerate to junior straight debt. Importantly, we will see that positive incentive effects from CoCo issuance are lost in this case. Indeed, the behavior of the model and, in particular, the value of equity, are discontinuous as we move from a regime in which conversion precedes default to a regime in which the order is reversed. We will see that this change can result from an increase in debt - either straight debt or CoCos — so we refer to this phenomenon as debt-induced collapse.

Upon default, we assume that a fraction $(1-\alpha), 0 \leq \alpha \leq 1$, of the firm's asset value is lost to bankruptcy and liquidation costs. Letting $\tau_{b}$ denote the time at which bankruptcy

\footnotetext{
${ }^{3}$ Our discussion of cash flows is informal and used to provide additional insight into the model. For a rigorous formulation of the Leland-Toft model through cash flows, see Décamps and Villeneuve [8].
} 
is declared and $V_{\tau_{b}}$ the value of the firm's assets at that moment leaves the firm with $\alpha V_{\tau_{b}}$ after bankruptcy costs. These remaining assets are used first to repay creditors. If default occurs after conversion, only the straight debt remains at bankruptcy. If default occurs before conversion, the CoCos degenerate to junior debt and are repaid from any assets that remain after the senior debt is repaid.

\subsection{Liability Valuation}

Our model yields closed-form expressions for the values of the firm's liabilities. We proceed by taking the level of the default boundary $V_{b}$ as given and valuing each layer of the capital structure. We then derive the optimal level $V_{b}^{*}$, leading to the concept of debt-induced collapse.

We begin by limiting attention to the case $V_{b} \leq V_{c}$, which ensures that the firm does not default before conversion. ${ }^{4}$ With $V_{b}$ fixed, the default time $\tau_{b}$ is the first time the asset value $V_{t}$ is at or below $V_{b}$. To value a unit of straight debt at time $t$ that matures at time $t+T$, we discount the coupon stream earned over the interval $\left[t,(t+T) \wedge \tau_{b}\right]$ and the (partial) principal received at $(t+T) \wedge \tau_{b}$ to get a market value of

$$
\begin{aligned}
b\left(V_{t} ; T ; V_{b}\right)= & \mathbb{E}^{\mathbb{Q}}\left[e^{-r T} \mathbf{1}_{\left\{\tau_{b}>T+t\right\}} \mid V_{t}\right] \quad \text { (principal payment if no default) } \\
& +\mathbb{E}^{\mathbb{Q}}\left[e^{-r \tau_{b}} \mathbf{1}_{\left\{\tau_{b} \leq T+t\right\}} \cdot \frac{\alpha V_{\tau_{b}}}{P_{1}} \mid V_{t}\right] \quad \text { (payment at default) } \\
& +\mathbb{E}^{\mathbb{Q}}\left[\int_{0}^{\tau_{b} \wedge(T+t)} c_{1} e^{-r(u-t)} d u \mid V_{t}\right] \cdot \quad \text { (coupon payments) }
\end{aligned}
$$

To simplify notation, we will henceforth take $t=0$ and omit the conditional expectation given $V_{t}$, though it should be understood that the value of each liability is a function of the current value $V$ of the firm's assets.

Recall that the debt maturity $T$ is exponentially distributed with density $m \exp (-m T)$, and the total par value is $P_{1}$. The total market value of straight debt outstanding is then

$$
\begin{aligned}
B\left(V ; V_{b}\right) & =P_{1} \int_{0}^{\infty} b\left(V_{t} ; T ; V_{b}\right) m e^{-m T} d T \\
& =P_{1}\left(\frac{m+c}{m+r}\right) \mathbb{E}^{\mathbb{Q}}\left[1-e^{-(m+r) \tau_{b}}\right]+\mathbb{E}^{\mathbb{Q}}\left[e^{-(m+r) \tau_{b}} \alpha V_{\tau_{b}}\right]
\end{aligned}
$$

The market value of a CoCo combines the value of its coupons, its principal, and its potential conversion to equity. To distinguish the equity value the CoCo investors receive after conversion

\footnotetext{
${ }^{4}$ In a model with jumps, the default time $\tau_{b}$ and conversion time $\tau_{c}$ may coincide, even if $V_{b}<V_{c}$. We adopt the convention that events occur in the order implied by the barrier levels, so in this case the CoCos would be treated as having converted when the firm's assets are liquidated in bankruptcy. For the case $V_{b}=V_{c}$, context determines the assumed order of events as follows: when we discuss $V_{b} \leq V_{c}$, we mean that conversion precedes bankruptcy, and when we discuss $V_{b} \geq V_{c}$ we mean the opposite.
} 
from equity value before conversion or without the possibility of conversion, we adopt the following notation:

- $E^{\mathrm{BC}}$ denotes equity value before conversion for the original firm, one with $P_{1}$ in straight debt and $P_{2}$ in CoCos;

- $E^{\mathrm{PC}}$ denotes post-conversion equity value and thus refers to a firm with $P_{1}$ in straight debt and no CoCos;

- $E^{\mathrm{NC}}$ denotes no-conversion equity value, which refers to a firm with $P_{1}$ in straight debt and $P_{2}$ in non-convertible junior debt.

Each of these is a function of the current asset value $V$ and a default barrier $V_{b}$. We will use the same superscripts to differentiate total firm value and other quantities as needed.

With this convention, a CoCo with maturity $T$ and unit face value has market value

$$
\begin{aligned}
d\left(V ; T ; V_{b}\right)= & \mathbb{E}^{\mathbb{Q}}\left[e^{-r T} \mathbf{1}_{\left\{\tau_{c}>T\right\}}\right]+\mathbb{E}^{\mathrm{Q}}\left[\int_{0}^{T \wedge \tau_{c}} c_{2} e^{-r s} d s\right] \\
& +\frac{\Delta}{1+\Delta P_{2}} \mathbb{E}^{\mathbb{Q}}\left[e^{-r \tau_{c}} E^{\mathrm{PC}}\left(V_{\tau_{c}} ; V_{b}\right) \mathbf{1}_{\left\{\tau_{c}<T\right\}}\right] . \quad \text { (conversion value) }
\end{aligned}
$$

In writing $E^{\mathrm{PC}}\left(V_{\tau_{c}} ; V_{b}\right)$, we are taking the value of post-conversion equity when the underlying asset value is at $V_{\tau_{c}}$ and the default barrier remains at $V_{b}$. At conversion, the CoCo investors collectively receive $\Delta P_{2}$ shares of equity, giving them a fraction $\Delta P_{2} /\left(1+\Delta P_{2}\right)$ of the firm; dividing this by $P_{2}$ yields the amount that goes to a CoCo with a face value of 1 . The total market value of CoCos outstanding is then

$$
\begin{aligned}
& D\left(V ; V_{b}\right)=P_{2} \int_{0}^{+\infty} d\left(V ; T ; V_{b}\right) m e^{-m T} d T \\
= & P_{2}\left(\frac{c_{2}+m}{m+r}\right)\left(1-\mathbb{E}^{\mathrm{Q}}\left[e^{-(r+m) \tau_{c}}\right]\right)+\frac{\Delta P_{2}}{1+\Delta P_{2}} \mathbb{E}^{\mathrm{Q}}\left[e^{-(r+m) \tau_{c}} E^{\mathrm{PC}}\left(V_{\tau_{c}} ; V_{b}\right)\right] .
\end{aligned}
$$

To complete the calculation in (2.6), it remains to determine the post-conversion equity value $E^{\mathrm{PC}}\left(V_{\tau_{c}} ; V_{b}\right)$. We derive this value by calculating total firm value and subtracting the value of debt. After conversion, the firm has only one class of debt, so

$$
E^{\mathrm{PC}}\left(V_{\tau_{c}} ; V_{b}\right)=F^{\mathrm{PC}}\left(V_{\tau_{c}} ; V_{b}\right)-B\left(V_{\tau_{c}} ; V_{b}\right)
$$


where $F^{\mathrm{PC}}\left(V_{\tau_{c}} ; V_{b}\right)$ is the total firm value after conversion:

$$
\begin{aligned}
F^{\mathrm{PC}}\left(V_{\tau_{c}} ; V_{b}\right) & =\underbrace{V_{\tau_{c}}}_{\text {unleveraged firm value }}+\underbrace{\mathbb{E}^{\mathrm{Q}}\left[\int_{\tau_{c}}^{\tau_{b}} \kappa c_{1} P_{1} e^{-r s} d s \mid V_{\tau_{c}}\right]}_{\text {tax benefits }}-\underbrace{\mathbb{E}^{\mathrm{Q}}\left[e^{-r\left(\tau_{b}-\tau_{c}\right)}(1-\alpha) V_{\tau_{b}} \mid V_{\tau_{c}}\right]}_{\text {bankruptcy costs }} \\
& =V_{\tau_{c}}+\frac{\kappa c_{1} P_{1}}{r}\left(1-\mathbb{E}^{\mathrm{Q}}\left[e^{-r\left(\tau_{b}-\tau_{c}\right)} \mid V_{\tau_{c}}\right]\right)-\mathbb{E}^{\mathrm{Q}}\left[e^{-r\left(\tau_{b}-\tau_{c}\right)}(1-\alpha) V_{\tau_{b}} \mid V_{\tau_{c}}\right] \\
& =: V_{\tau_{c}}+T B_{1}-\operatorname{BCOST.}
\end{aligned}
$$

The conversion of the CoCos does not affect the value of the senior debt, so the valuation expression in (2.5) applies to $B\left(V_{\tau_{c}} ; V_{b}\right)$ in $(2.7)$.

To find the value of equity before conversion, we again derive the total firm value and subtract the debt value. We continue to limit attention to the case $V_{b} \leq V_{c}$. The tax benefit from issuing CoCos terminates at the conversion time $\tau_{c}$, if the CoCo coupons are in fact tax-deductible. So, the firm value before conversion is

$$
\begin{aligned}
F^{\mathrm{BC}}\left(V ; V_{b}\right)= & V+\underbrace{\frac{\kappa c_{1} P_{1}}{r}\left(1-\mathbb{E}^{\mathrm{Q}}\left[e^{-r \tau_{b}}\right]\right)}_{\text {tax benefits from straight bonds }}+\underbrace{\frac{\kappa c_{2} P_{2}}{r}\left(1-\mathbb{E}^{\mathrm{Q}}\left[e^{-r \tau_{c}}\right]\right)}_{\text {tax benefits from CoCos }} \\
& -\mathbb{E}^{\mathrm{Q}}\left[e^{-r \tau_{b}}(1-\alpha) V_{\tau_{b}}\right] \\
=: & V+T B_{1}+T B_{2}-\text { BCOST. }
\end{aligned}
$$

The market value of the firm's equity is given by

$$
E^{\mathrm{BC}}\left(V ; V_{b}\right)=F^{\mathrm{BC}}\left(V ; V_{b}\right)-B\left(V ; V_{b}\right)-D\left(V ; V_{b}\right)
$$

A similar calculation leads to closed-form liability evaluation if conversion does not occur prior to bankruptcy, i.e., $V_{b}>V_{c}$. In this case, CoCo bonds degenerate to non-convertible junior debt. Upon default, CoCo holders are repaid from whatever assets remain after liquidation and payment of senior debt. Before default, the total market value of straight debt is

$$
B\left(V ; V_{b}\right)=P_{1}\left(\frac{m+c_{1}}{m+r}\right) \mathbb{E}^{\mathbb{Q}}\left[1-e^{-(m+r) \tau_{b}}\right]+\mathbb{E}^{\mathbb{Q}}\left[e^{-(m+r) \tau_{b}}\left(\alpha V_{\tau_{b}} \wedge P_{1}\right)\right]
$$

leaving a CoCo value of

$$
D\left(V ; V_{b}\right)=P_{2}\left(\frac{m+c_{2}}{m+r}\right) \mathbb{E}^{\mathbb{Q}}\left[1-e^{-(m+r) \tau_{b}}\right]+\mathbb{E}^{\mathbb{Q}}\left[e^{-(m+r) \tau_{b}}\left(\alpha V_{\tau_{b}}-P_{1}\right)^{+}\right] .
$$

Total firm value in this case is given by

$$
F^{\mathrm{BC}}\left(V ; V_{b}\right)=V+\left(\frac{\kappa c_{1} P_{1}}{r}+\frac{\kappa c_{2} P_{2}}{r}\right)\left(1-\mathbb{E}^{\mathrm{Q}}\left[e^{-r \tau_{b}}\right]\right)-\mathbb{E}^{\mathrm{Q}}\left[e^{-r \tau_{b}}(1-\alpha) V_{\tau_{b}}\right]
$$


The only difference between this expression and (2.8) lies in the tax shield provided by the CoCo coupon payments, which now terminates at default rather than conversion. Equity value in the case $V_{b}>V_{c}$ now follows from (2.9) using these expressions.

All pieces (2.5)-(2.11) of the capital structure of the firm can be explicitly evaluated through expressions for the joint transforms of hitting times $\tau_{b}$ or $\tau_{c}$ and asset value $V$ given explicitly by Kou [18] and Kou and Wang [19]. Appendix A of this paper contains additional information.

In (2.5) and (2.11) we have implicitly made a standard assumption that the asset value recovered in bankruptcy does not exceed the total amount due to bond holders. Indeed, Chen and Kou [7] show that this property holds at the endogenous default time chosen by shareholders. With the addition of CoCos, we make the further assumption that the conversion ratio satisfies

$$
1 / \Delta \geq \alpha V_{c}-P_{1}-P_{2}
$$

The expression on the left is the price per share applied to the CoCos at conversion; the expression on the right is the price per share the original equity holders could get by liquidating the firm and paying off all debt at $V=V_{c}$. If (2.12) were violated, the original equity holders might be motivated to liquidate the firm even when it has strictly positive equity value. Unless $V_{c}$ is very high, we expect the right side of (2.12) to be negative and the condition therefore satisfied by any $\Delta>0$. The implication of (2.12) is, then, that the conversion price $1 / \Delta$ needs to be commensurate with the conversion trigger.

\subsection{The Bail-In Case}

In the bail-in case, conversion of debt to equity occurs when the firm would not otherwise be viable, rather than at an exogenously specified trigger. We model this by taking $V_{c}=V_{b}$, with the understanding that conversion occurs just before what would otherwise be bankruptcy. We set $\Delta=\infty$ so the original shareholders are wiped out, and the firm is taken over by the bail-in investors. As bankruptcy is avoided, we assume that no bankruptcy costs are incurred, so $\alpha=1$. Just after conversion, the firm continues to operate, now with just $P_{1}$ in debt outstanding.

\section{Optimal Default and Debt-Induced Collapse}

Having valued the firm's equity at an arbitrary default barrier $V_{b}$, we now proceed to derive the equity holder's optimal default barrier $V_{b}^{*}$. This analysis takes the debt levels $P_{1}$ and $P_{2}$ to be fixed. Once we characterize the optimal default barrier for arbitrary $P_{1}$ and $P_{2}$, we can go a step further and optimize the full capital structure, a problem addressed in Section 4 . In 
the following we assume that coupon payments on the CoCos are tax deductible, but similar results hold otherwise, with straightforward modifications.

As in Section 2, we denote by $E^{\mathrm{PC}}\left(V ; V_{b}\right)$ the post-conversion equity value for a firm with asset value $V$ and default barrier $V_{b}$. After conversion, we are dealing with a conventional firm, meaning one without CoCos. In such a firm, the equity holders choose the default barrier $V_{b}$ to maximize the value of equity subject to the constraint that equity value can never be negative; that is, they solve

$$
\max _{V_{b}} E^{\mathrm{PC}}\left(V ; V_{b}\right)
$$

subject to the limited liability constraint

$$
E^{\mathrm{PC}}\left(V^{\prime} ; V_{b}\right) \geq 0, \quad \text { for all } V^{\prime} \geq V_{b}
$$

The limited liability constraint ensures that the chosen $V_{b}$ is feasible. Without this condition, a choice of $V_{b}$ that maximizes $E^{\mathrm{PC}}\left(V ; V_{b}\right)$ at the current asset level $V$ might entail sustaining a negative value of equity at some asset level between $V_{b}$ and $V$, which is infeasible. Denote the solution to this problem by $V_{b}^{\mathrm{PC}}$.

Before conversion, when the firm's liabilities include CoCos, equity value is given by $E^{\mathrm{BC}}\left(V ; V_{b}\right)$, and the shareholders would like to choose $V_{b}$ to maximize this value. If they choose $V_{b}<V_{c}$, conversion will precede bankruptcy, and following conversion they - and the new shareholders who were formerly CoCo holders - will face an equity maximization problem of the type in (3.1). Hence, before conversion the equity holders face a commitment problem, in the sense that they cannot necessarily commit to holding $V_{b}$ at the same level after conversion that they would have chosen before conversion. Anticipating this effect, they will choose $V_{b}=V_{b}^{\mathrm{PC}}$ if they choose $V_{b}<V_{c}$. Thus, before conversion, equity holders will choose $V_{b}$ to solve

$$
\max _{V_{b}} E^{\mathrm{BC}}\left(V ; V_{b}\right)
$$

subject to the limited liability constraint

$$
E^{\mathrm{BC}}\left(V^{\prime} ; V_{b}\right) \geq 0, \quad \text { for all } V^{\prime} \geq V_{b}
$$

and the commitment condition that $V_{b}=V_{b}^{\mathrm{PC}}$ if $V_{b}<V_{c}$. Let $V_{b}^{*}$ denote the solution to this problem.

Chen and Kou [7] have solved the optimal default barrier problem with only straight debt, and this provides the solution for the post-conversion firm: $V_{b}^{\mathrm{PC}}=P_{1} \epsilon_{1}$, where $\epsilon_{1}$ depends on $c_{1}, m, \kappa$ and $\alpha$ but is independent of the capital structure and $V$. See the appendix for an explicit expression. Recall that $E^{\mathrm{NC}}\left(V ; V_{b}\right)$ denotes the value of equity if the $P_{2}$ in CoCos is 
replaced with non-convertible junior debt in the original firm. Extending Chen and Kou [7], we can express the optimal default barrier for this firm as $V_{b}^{\mathrm{NC}}=P_{1} \epsilon_{1}+P_{2} \epsilon_{2}$, where $\epsilon_{2}$ is defined analogously to $\epsilon_{1}$ using $c_{2}$ instead of $c_{1}$. We always have $V_{b}^{\mathrm{PC}} \leq V_{b}^{\mathrm{NC}}$ because increasing the amount of non-convertible debt while holding everything else fixed raises the default barrier. We can now characterize the optimal default barrier with CoCos.

Theorem 1. For a firm with straight debt and with CoCos that convert at $V_{c}$, the optimal default barrier $V_{b}^{*}$ has the following property: Either

$$
V_{b}^{*}=V_{b}^{P C} \leq V_{c} \quad \text { or } \quad V_{b}^{*}=V_{b}^{N C} \geq V_{c}
$$

Moreover, $V_{b}^{P C}$ is optimal whenever it is feasible, meaning that it preserves the limited liability of equity.

This result reduces the possible default barriers for a firm with CoCos to just two candidates, each of which corresponds to the default barrier for a firm without CoCos. The second case is a candidate only if, without the conversion feature, it would be optimal to default at an asset level higher than the trigger $V_{c}$. This can occur only if the first case does not yield a feasible solution.

We will see that a firm can move from the first case in (3.2) to the second case by increasing its load of either straight debt or CoCos. The transition is discontinuous, creating a jump up in the default barrier and a drop in equity value. We refer to this phenomenon as debt-induced collapse. This phenomenon is not present without CoCos (or with bail-in debt). Moreover, we will see that the positive incentive effects that result from CoCos under the first case in (3.2) disappear following the collapse.

To illustrate, we consider an example. The heavy solid line in Figure 1 shows equity value as a function of asset value for the NC firm, in which the CoCos are replaced by junior debt. The optimal default barrier $V_{b}^{\mathrm{NC}}$ is at 93 , and the NC equity value and its derivative are equal to zero at this point. If the conversion trigger $V_{c}$ is below 93 (two cases are considered in the figure), then $V_{b}=V_{b}^{\mathrm{NC}}=93$ is a feasible default level for the original firm because the resulting equity values are consistent with limited liability. The optimal post-conversion default barrier is $V_{b}^{\mathrm{PC}}=58$. Suppose the conversion trigger is at $V_{c}=65$, and suppose the original shareholders of the original firm with CoCos attempt to set the default barrier at $V_{b}=58$. The dashed line shows the resulting equity value. At higher asset values, the dashed lines is above the solid line, suggesting that equity holders would prefer to set the default barrier at 58 than at 93 . However, the dashed line is not a feasible choice because it creates negative equity values at lower asset 


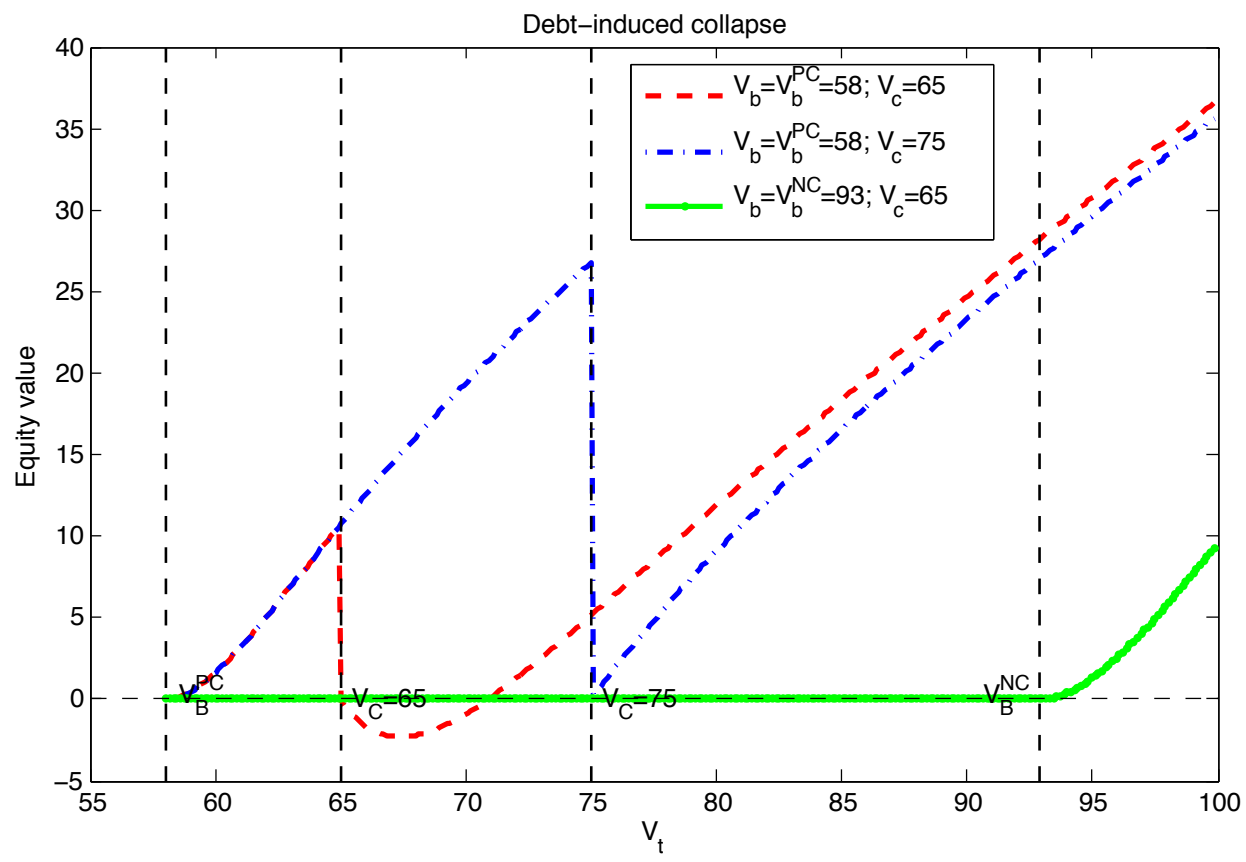

Figure 1: Candidate equity value as a function of asset value in three scenarios. The heavy solid (green) line reflects default at $V_{b}^{\mathrm{NC}}=93$, prior to conversion. The other two lines reflect default at $V_{b}^{\mathrm{PC}}=58$ with two different conversion triggers. With $V_{c}=65$, equity becomes negative so $V_{b}^{\mathrm{PC}}$ is infeasible and default occurs at $V_{b}^{\mathrm{NC}}$. With $V_{c}=75$, default at $V_{b}^{\mathrm{PC}}$ is feasible, and it is optimal because it yields higher equity than $V_{b}^{\mathrm{NC}}$.

levels; the best the shareholders can do in this case is to set $V_{b}=93$. If the conversion trigger were at $V_{c}=75$, a default barrier of $V_{b}=V_{b}^{\mathrm{PC}}=58$ would be feasible because the resulting equity values (the dash-dot line) remain positive; in fact, this choice would then be optimal. If we imagine starting with the conversion trigger at 75 and gradually decreasing it toward 65 , at some level of $V_{c}$ in between the default barrier jumps up from 58 to 93 , and the equity curve collapses down to the heavy solid line showing the equity curve for the NC firm.

In the bail-in case, the original equity holders are effectively choosing $V_{c}$ because their default is a conversion that transfers ownership to the new shareholders. After conversion, the new shareholders will choose default barrier $V_{b}^{\mathrm{PC}}$. Before conversion, the original equity value is given by $E^{\mathrm{BC}}$, evaluated with $\Delta=\infty$. In maximizing the value of their claim, the original equity holders will choose a level of $V_{c}$ consistent with limited liability, $E^{\mathrm{BC}}\left(V ; V_{b}^{\mathrm{PC}}\right) \geq 0$, for all $V \geq V_{c}$. The value of equity changes continuously with $V_{c}$ and with the debt levels $P_{1}$ and $P_{2}$ (this can be seen from the expression (A.1) given in the appendix) so there is no phenomenon of debt-induced collapse.

As the example of Figure 1 illustrates, the threshold for debt-induced collapse depends on 
the level of debt relative to the conversion trigger $V_{c}$ : a higher conversion trigger allows a higher level of debt. Indeed, because we have $V_{b}^{\mathrm{NC}}=P_{1} \epsilon_{1}+P_{2} \epsilon_{2}$, debt-induced collapse is impossible if $V_{c}$ is greater than this linear combination of the debt levels. In the next theorem, we provide conditions for debt-induced collapse in terms of limits on the levels of straight debt and CoCos.

Theorem 2. There exist upper bounds on the amount of straight debt and CoCos above which debt-induced collapse ensues. Formally, there exist $\bar{P}_{1}$ and $\bar{P}_{2}$, where $\bar{P}_{2}$ depends on $P_{1}$, such that the following holds:

- If either $P_{1}>\bar{P}_{1}$ or $P_{2}>\bar{P}_{2}$, then we have debt-induced collapse.

- If $0 \leq P_{1} \leq \bar{P}_{1}$ and $0 \leq P_{2} \leq \bar{P}_{2}$, then debt-induced collapse does not occur.

The critical levels $\bar{P}_{1}$ and $\bar{P}_{2}$ are derived in the appendix.

The condition $P_{1} \leq \bar{P}_{1}$ is equivalent to $V_{b}^{\mathrm{PC}} \leq V_{c}$, and, when this holds, $P_{2} \leq \bar{P}_{2}$ is equivalent to $E^{\mathrm{BC}}\left(V ; V_{b}^{\mathrm{PC}}\right) \geq 0$ for all $V \geq V_{c}$. The limits on the debt levels are thus the conditions needed to ensure feasibility (hence optimality) of $V_{b}^{\mathrm{PC}}$. We illustrate these debt limits through numerical examples. We fix the parameters in Table 1 and vary the average maturity $1 / m$, and the amount of straight debt $P_{1}$.

\begin{tabular}{lr|l} 
Parameter & & Value \\
\hline initial asset value & $V_{0}$ & 100 \\
risk free rate & $r$ & $6 \%$ \\
volatility & $\sigma$ & $15 \%$ \\
payout rate & $\delta$ & $1 \%$ \\
tax rate & $\kappa$ & $35 \%$ \\
jump intensity & $\lambda_{f}$ & 0.1 \\
firm specific jump exponent & $\eta$ & 2 \\
coupon rates & $\left(c_{1}, c_{2}\right)$ & $(r+3 \%, r+3 \%)$ \\
bankruptcy loss & $(1-\alpha)$ & $50 \%$ \\
\hline
\end{tabular}

Table 1: Base case parameters. Asset returns have a total volatility (combining jumps and diffusion) of $27 \%$. On average every 10 years a jump costs the firm a third of its value. The number of shares $\Delta$ issued at conversion is set such that the market value of shares delivered is the same as the face value of the converted debt if conversion happens at exactly $V_{c}$.

Figure 2 shows the maximum amount of CoCos and the maximum leverage ratio that can be sustained without debt-induced collapse, with a conversion barrier $V_{c}=75$. The mean maturity ranges from $1 / m=0.1$ years to $1 / m=10$ years. In the first plot we show $\bar{P}_{2}$ as a function of $P_{1}$. The intersection of each curve with the x-axis represents $\bar{P}_{1}$. For example a 
firm with a mean debt maturity of $1 / m=4$ years and face value $P_{1}=90$ can only add $\bar{P}_{2}=12$ CoCos to the capital structure. If the firm adds more CoCos, debt-induced collapse occurs. The second plot shows the same relationship, but now in terms of leverage. For a firm that chooses a capital structure with $P_{1}$ and $P_{2}$, we calculate the resulting total value of the firm $F$. The ratios $P_{1} / F$ and $P_{2} / F$ are the leverage ratios for straight debt and CoCos. A firm with debt maturity of 10 years and a straight debt leverage of $91 \%$ can increase the CoCo leverage only up to $6 \%$. Finally, in the third plot we show the total leverage $\left(P_{1}+P_{2}\right) / F$ as a function of straight debt leverage. A firm with a debt maturity of 1 year cannot lever up to more than $80 \%$ without triggering debt-induced collapse, regardless of how it chooses its capital structure.
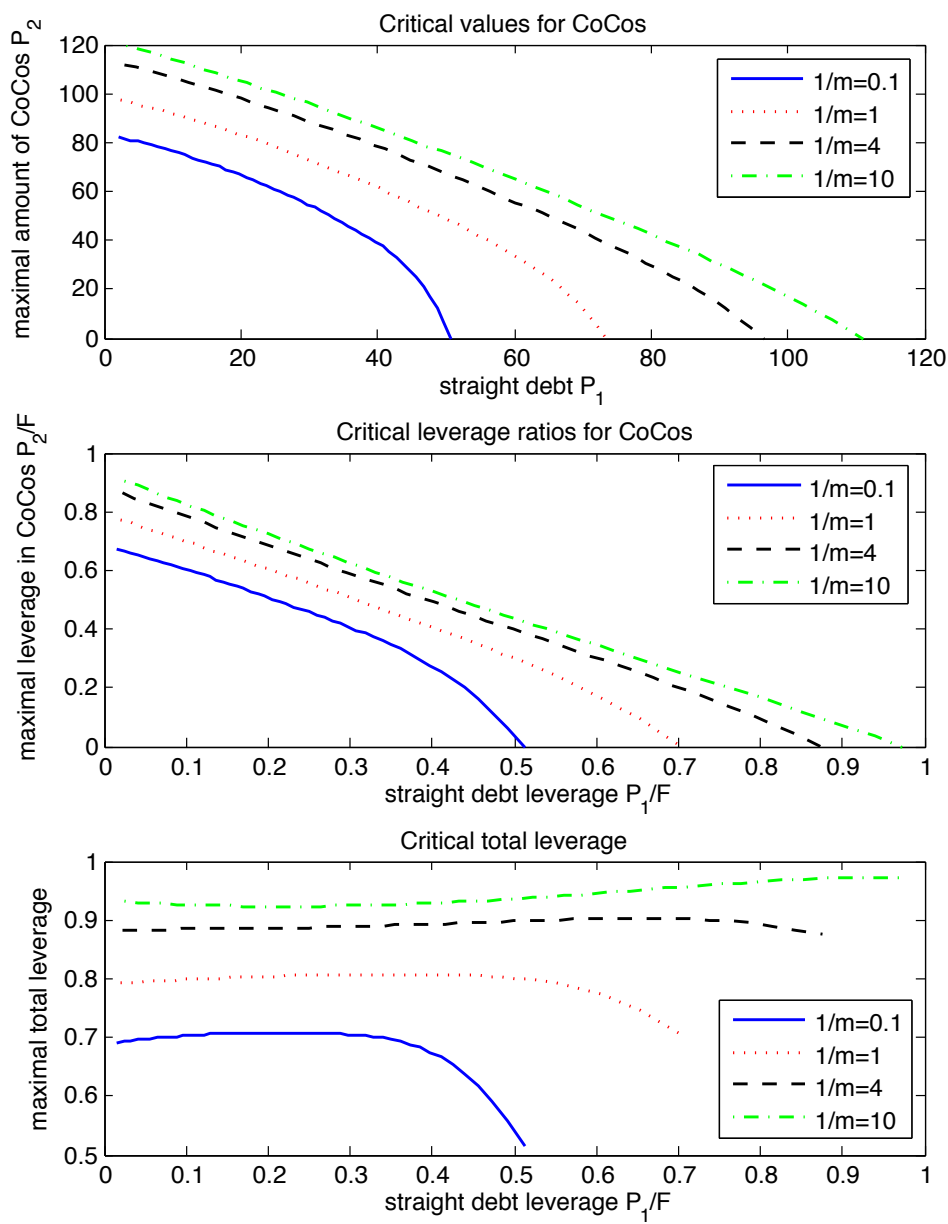

Figure 2: Top: Critical values of CoCo bonds $\bar{P}_{2}$ as a function of straight debt $P_{1}$ for different mean maturities and $V_{c}=75$. Middle: Critical leverage ratios of CoCo bonds $\bar{P}_{2} / F$ as a function of straight debt leverage $P_{1} / F$. Bottom: Critical leverage $\left(P_{1}+\bar{P}_{2}\right) / F$ as a function of straight debt leverage $P_{1} / F$. 
As we have noted before, the optimal default barrier $V_{b}^{\mathrm{PC}}=P_{1} \epsilon_{1}$ is proportional to the amount of straight debt. If $V_{c}$ is far above $V_{b}^{\mathrm{PC}}$, a large amount of CoCos can be issued. A short mean maturity $1 / m$ results in a higher default barrier $V_{b}^{\mathrm{PC}}$ and hence also in a lower critical level $\bar{P}_{2}$. If the amount of straight debt is high, this also increases $V_{b}^{\mathrm{PC}}$ and the same effect takes place.

\section{Implications for Optimal Capital Structure and Regulation}

In the previous section, we showed that an increase in either straight debt or CoCos can precipitate debt-induced collapse, viewing the debt levels $P_{1}$ and $P_{2}$ as exogenous. In this section, we examine the implications of debt-induced collapse for the firm's optimal choice of debt levels and for the effect of regulatory constraints on these debt levels.

As in Leland [21] and much of the subsequent capital structure literature, we have taken the default barrier to maximize the value of equity, and we now take the debt levels to maximize total firm value. The coupon rates $c_{1}, c_{2}$ are set exogenously.

A firm that issues only straight debt (which we may think of as a post-conversion firm), chooses $P_{1}$ to maximize the firm value $F^{\mathrm{PC}}$, solving

$$
\max _{P_{1}} F^{\mathrm{PC}}=\max _{P_{1}}\left(V+T B_{1}-B C O S T\right)
$$

In the absence of CoCos, this reduces to the problem studied in Chen and Kou [7], who showed that firm value is strictly concave in $P_{1}$; for each $V$ there is a unique debt level solving (4.1), which we denote by $P_{1}^{\mathrm{PC}}$. This debt level optimally balances the tradeoff between tax benefits $T B_{1}$ and bankruptcy costs BCOST.

If we allow the firm to issue CoCos in addition to straight debt, the optimization problem changes to maximizing the before-conversion firm value

$$
\max _{P_{1}, P_{2}} F^{\mathrm{BC}}=\max _{P_{1}, P_{2}}\left(V+T B_{1}+T B_{2}-B C O S T\right)
$$

with $T B_{2}$ the tax benefits from CoCos. To simplify the exposition and convey the main points, we assume the coupon rates for the two types of debt are the same $\left(c_{1}=c_{2}\right)$, but the arguments can easily be generalized.

We first consider the behavior of the firm value $F^{\mathrm{BC}}$ over the region in which $P_{1} \leq \bar{P}_{1}$ and $P_{2} \leq \bar{P}_{2}$, recalling that $\bar{P}_{1}$ and $\bar{P}_{2}$ are the upper limits on the two types of debt that preclude debt-induced collapse. For debt levels in this region, we know from Theorem 2 that the optimal default barrier $V_{b}^{*}$ equals $V_{b}^{\mathrm{PC}}$ and is thus independent of $P_{2}$, the level of CoCo issuance. Within 
this region, we may write the firm value as

$$
F^{\mathrm{BC}}=V+T B_{1}\left(P_{1}\right)+T B_{2}\left(P_{2}\right)-B \operatorname{COST}\left(P_{1}\right)=F^{\mathrm{PC}}\left(P_{1}\right)+T B_{2}\left(P_{2}\right) .
$$

The other region to consider has at least one of the two debt levels $P_{1}, P_{2}$ above the threshold for debt-induced collapse. Within this region, CoCos degenerate to ordinary debt, and with $c_{1}=c_{2}$ the two types of debt are perfect substitutes, so the debt levels affect firm value only through their total $P_{1}+P_{2}$. By combining the two cases, we get

$$
F^{\mathrm{BC}}= \begin{cases}F^{\mathrm{PC}}\left(P_{1}\right)+T B_{2}\left(P_{2}\right), & \text { if } P_{1} \leq \bar{P}_{1} \text { and } P_{2} \leq \bar{P}_{2} ; \\ F^{\mathrm{PC}}\left(P_{1}+P_{2}\right), & \text { otherwise }\end{cases}
$$

In the first case, we know that the tax benefit from CoCo issuance is strictly increasing in $P_{2}$, so for any choice of $P_{1}$, the optimal $P_{2}$ is $P_{2}^{*}=\bar{P}_{2}\left(P_{1}\right)$. Now suppose that $P_{1}^{\mathrm{PC}} \leq \bar{P}_{1}$, with $P_{1}^{\mathrm{PC}}$ the level maximizing the value of the post-conversion firm in (4.1). In this case, we claim that the optimal level of senior debt for the before-conversion firm satisfies $P_{1}^{*} \leq P_{1}^{\mathrm{PC}}$. Within the no-collapse region, increasing $P_{1}$ beyond $P_{1}^{\mathrm{PC}}$ would decrease both $F^{\mathrm{PC}}\left(P_{1}\right)$ (by the optimality of $P_{1}^{\mathrm{PC}}$ ) and $T B_{2}\left(\bar{P}_{2}\left(P_{1}\right)\right)$ (because $\bar{P}_{2}$ is decreasing in $\left.P_{1}\right)$. For debt levels $\left(P_{1}, P_{2}\right)$ outside the no-collapse region, we have

$$
F^{\mathrm{PC}}\left(P_{1}+P_{2}\right) \leq F^{\mathrm{PC}}\left(P_{1}^{\mathrm{PC}}\right) \leq F^{\mathrm{PC}}\left(P_{1}^{*}\right)+T B_{2}\left(\bar{P}_{2}\left(P_{1}^{*}\right)\right)
$$

We can summarize these points as follows:

Proposition 1. The optimal capital structure $\left(P_{1}^{*}, P_{2}^{*}\right)$ has the following properties. (i) If the firm's optimal choice does not produce debt-induced collapse, then it has the form

$$
P_{1}^{*} \leq P_{1}^{P C} \text { and } P_{2}^{*}=\bar{P}_{2}\left(P_{1}^{*}\right)
$$

(ii) If the coupon rates $c_{1}, c_{2}$ are equal and the firm's optimal choice does produce debt-induced collapse, then $P_{1}^{*}+P_{2}^{*}=P_{1}^{P C}$. All combinations of $P_{1}, P_{2}$ with the same value of $P_{1}+P_{2}$ and with $P_{1}>\bar{P}_{1}$ or $P_{2}>\bar{P}_{2}$ achieve the same firm value. (iii) If $P_{1}^{P C} \leq \bar{P}_{1}$, then the firm's optimal choice does not produce debt-induced collapse.

This result shows that the optimal capital structure can take two possible forms. In (i), the option to issue CoCos lead the firm to reduce (or at least not to increase) its level of senior debt. In fact, first-order conditions for optimality imply that this inequality will typically be strict because the constraint $P_{2}^{*} \leq \bar{P}_{2}\left(P_{1}^{*}\right)$ has a positive shadow cost, implying a strict reduction in senior debt. Part (ii) reflects the fact that in the region of debt-induced collapse, 
the CoCos degenerate to straight debt, and, with equal coupons, the two types of debt are perfect substitutes. Part (iii) provides a simple sufficient condition that ensures the firm's optimal choice will not produce debt-induced collapse.

The alternatives presented in Proposition 1 have implications for regulation. In case (i), a regulator can control the firm's default probability by controlling the level of senior debt. So long as the firm's debt levels are in the no-collapse region, the default barrier is strictly increasing in $P_{1}$, so reducing $P_{1}$ makes default less likely. If a regulator limits senior debt to a level lower than the firms optimum, so that $P_{1}<P_{1}^{*} \leq P_{1}^{\mathrm{PC}}$, the firm will increase its CoCo issuance to $\bar{P}_{2}\left(P_{1}\right)$. In so doing, it recovers at least part of the firm value lost through the reduction in senior debt without changing the probability of default, because the additional CoCos do not move the default barrier.

The situation is quite different in the second case of Proposition 1, where the firm's optimal choice $\left(P_{1}^{*}, P_{2}^{*}\right)$ puts it in the region of debt-induced collapse. In this case, limiting $P_{1}$ is ineffective because the two types of debt are perfect substitutes, and any increase in $P_{2}$ without an offsetting decrease in $P_{1}$ increases the probability of default. The regulator can ensure that the firm will optimally choose debt levels in the no-collapse region by requiring that the conversion trigger be set sufficiently high:

Corollary 1. If the conversion trigger satisfies $V_{c}>P_{1}^{P C_{\epsilon_{1}}}$, then the firm's optimal capital structure is in the no-collapse region $P_{1} \leq \bar{P}_{1}$ and $P_{2} \leq \bar{P}_{2}$.

This is a direct consequence of our previous results. If the firm's optimal capital structure produced debt-induced collapse, it would have to satisfy $P_{1}^{*}+P_{2}^{*}=P_{1}^{\mathrm{PC}}$, and, by Theorem 1 , the optimal default barrier would satisfy $V_{b}^{*}=\left(P_{1}^{*}+P_{2}^{*}\right) \epsilon_{1}$. But the condition in the corollary would then imply $V_{b}^{*}<V_{c}$, contradicting debt-induced collapse. The contradiction implies that the firm's optimal choice must be in the no-collapse region. A key feature of this result is that the quantities $P_{1}^{P C}$ and $\epsilon_{1}$ have nothing to do with CoCos - they are defined by a firm with only straight debt.

\section{The Impact of Debt Rollover}

In the previous section, we examined optimal debt levels from the perspective of maximizing firm value. In this section, we return to the shareholders' perspective to investigate the impact of debt rollover on equity value under various changes in capital structure.

The process of rolling debt is important to our analysis, so we briefly describe this feature of our model. Under our exponential maturity assumption, old debt is continuously maturing 
and new debt is continuously issued. Within each debt category, the coupon and the total par value outstanding remain constant; but while debt matures at par value, it is issued at market value. If the par value is greater, the difference is a cash shortfall that needs to be paid out by the firm; if the market value is greater, the difference generates additional cash for the firm. We refer to these as rollover costs - a positive cost in the first case, a negative cost in the second - and treat them the same way we treat coupon payments. Rollover costs will change as the firm's asset value changes, becoming larger as asset value declines, the firm gets closer to default, and the market value of its debt decreases. Rollover costs thus capture the increased yield demanded of riskier firms. ${ }^{5}$

The comparisons in this section are based on combinations of qualitative properties and numerical examples. For the numerical examples, we enrich the base model, expanding the capital structure through additional layers of straight debt and allowing two types of jumps in asset value. Details of these extensions and parameter values for the numerical illustrations are discussed in Appendix B. We use the parameters given there in Table 5. The firm initially funds 100 in assets with a total par value of 85 in non-convertible debt and 15 in equity or a combination of equity and CoCos. Under any change in capital structure, we recompute the optimal default barrier and recompute the value of the firm and its liabilities. Throughout this section, we limit ourselves to changes that keep the firm within the no-collapse region so that the CoCos do not degenerate to straight debt.

\subsection{Replacing Straight Debt with CoCos}

We begin by replacing some straight debt with CoCos. The consequences of the substitution are as follows.

- If coupon payments on CoCos are not tax deductible, then replacing straight debt with CoCos has the immediate effect of reducing firm value by reducing the value of the tax shield. Even if CoCo coupons are tax deductible, this benefit ends at conversion, so, other things being equal, the substitution still has the immediate impact of reducing firm value; see (2.8). The reduction in firm value has the direct effect of lowering the value of equity.

- However after conversion the firm will have less debt outstanding and lower debt service payments (coupons and rollover costs) than it would without the substitution of CoCos for straight debt. With lower debt service, more of the cash generated by the firm's assets

\footnotetext{
${ }^{5}$ Debt rollover also have important implications for asymmetric information and monitoring, as in Calomiris and Kahn [5], and liquidity risk, as in He and Xiong [15], but these features are outside the scope of our model.
} 
flows to equity holders in dividends. This reduces the default barrier $V_{b}^{*}$, which extends the life of the firm, reduces the bankruptcy cost and thus increases firm value in (2.8).

- We thus have two opposite effects on firm value: the reduced tax shield from CoCos reduces firm value, but the reduced default probability and bankruptcy cost increases firm value. In our numerical examples, we find that the second effect dominates over a wide range of parameter values, so that the net effect of replacing straight debt with CoCos is to increase firm value.

- Part of this increase in firm value is captured by debt holders because the reduced bankruptcy risk increases the value of the debt. Part of the increase is also captured by equity holders: the increased debt value reduces rollover costs which increases the flow of dividends. Thus, equity holders have a positive incentive to issue CoCos.

This conclusion contrasts with that of Albul et al. [1], who find that equity holders would never voluntarily replace straight debt with contingent convertibles. In their model, straight debt has infinite maturity and is never rolled. As a result, all of the benefit of reduced bankruptcy costs from CoCos is captured by debt holders. This difference highlights the importance of debt rollover in influencing incentives for equity holders, an effect we return to at several points.

The line marked with crosses in the left panel of Figure 3 shows the increase in equity value resulting from a substitution of one unit (market value) of CoCos for one unit (market value) of straight debt, plotted against the value of the firm's asset value. The conversion level $V_{c}$ is 75. Despite the dilutive effect of conversion, the benefit to equity holders of the substitution is greatest just above the conversion level and decreases as asset level increases. This follows from the fact that the benefit to equity holders derives from the reduction in bankruptcy costs, which is greater at lower asset values. We will discuss the other curves in the left panel shortly.

The right panel of Figure 3 incorporates a friction in the conversion of debt to equity. To this point, we have valued each security as the expected present value of its cash flows. In practice, the markets for debt and equity are segmented, and some bond investors may be unwilling (or unable under an investment mandate) to own equity. Such investors would value CoCos at less than their present value, and this effect could well move the price at which the market clears, given the comparatively small pool of investors focused on hybrid securities.

To capture this effect, we suppose that the equity received by CoCo investors at conversion is valued at $80 \%$ of market value. For example, we can think of CoCo investors as dumping their shares at a discount, with the discount reflecting a market impact that is only temporary and 

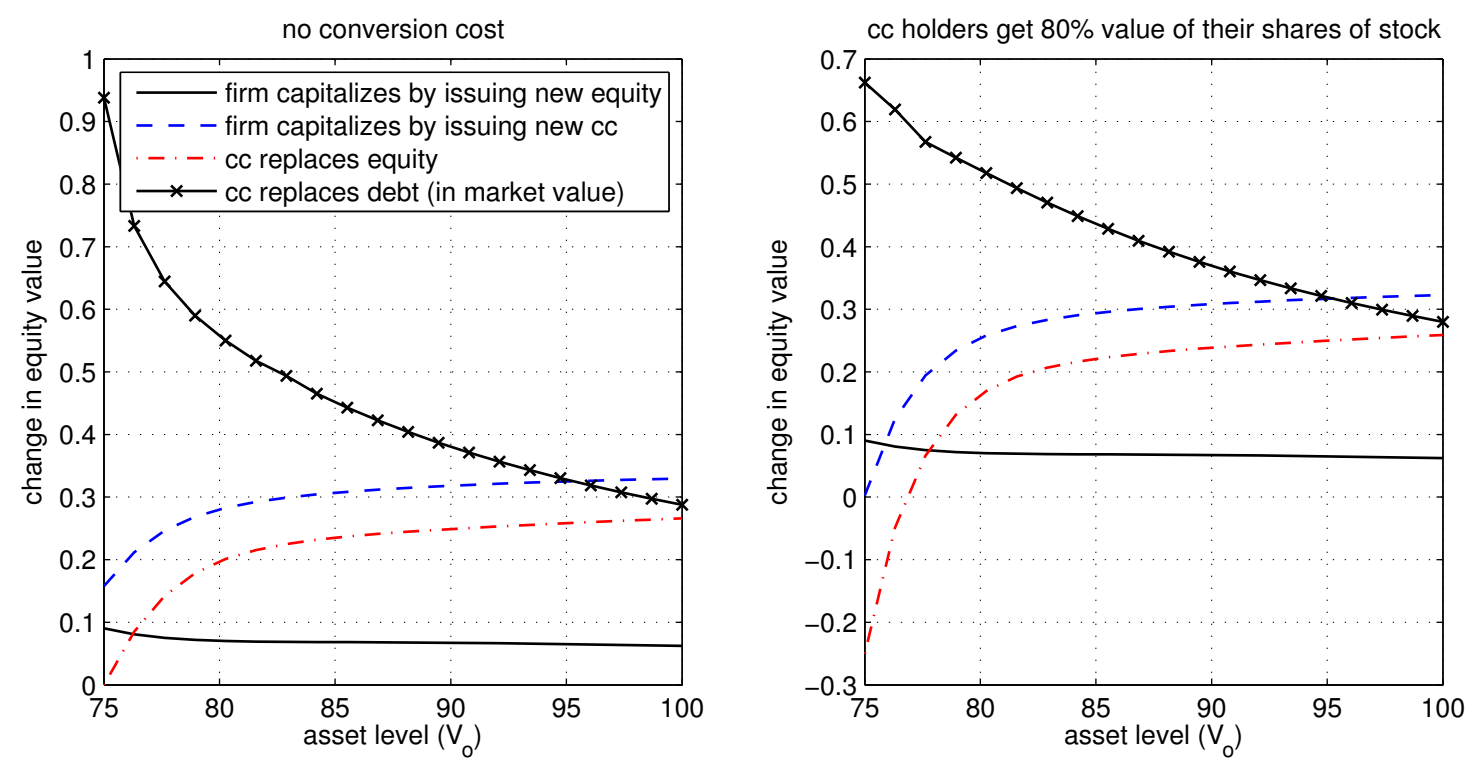

Figure 3: Change in equity value resulting from various changes in capital structure. In the right hand figure the CoCo holders dump their shares in the market following the conversion and as a result lose $20 \%$ value of their shares due price impact and transaction fees.

therefore does not affect the original equity holders. CoCo investors anticipate that they will not receive the full value of equity at conversion and thus discount the price of CoCos up front. This makes CoCos more expensive for the firm as a source of funding. The line marked with crosses in the right panel shows the benefit to equity holders of the same substitution examined in the left panel. As one would expect, the benefit is substantially reduced near the conversion trigger of 75 (comparing the two panels); at higher asset values, the difference between the cases vanishes, with the crossed lines in both panels near 0.3 at an asset level of 100 . To summarize: Segmentation between debt and equity investors creates a friction in conversion that reduces the benefit of issuing CoCos; this effect is especially pronounced near the conversion trigger.

\subsection{Increasing the Balance Sheet with CoCos}

We now consider the effects of issuing CoCos without an offsetting reduction in any other liabilities. The proceeds from issuing CoCos are used to scale up the firm's investments. The consequences of this change are as follows:

- Because the post-conversion debt outstanding is unchanged, the endogenous default barrier $V_{b}^{*}$ is unchanged, so long as the firm stay within the no-collapse region of debt levels.

- In this case, the risk of default decreases because an increase in assets moves the firm 
farther from the default barrier. The reduction in bankruptcy costs increases firm value and the value of straight debt. The additional tax shield from issuing CoCos (assuming their coupons are tax-deductible) further increases firm value.

- Shareholders benefit from the increase in firm value combined with the decrease in rollover costs for straight debt and the increase in cash generated from the larger asset base. These benefits work in the opposite direction of the increase in coupon payments required for the new CoCos.

- With a sufficiently large CoCo issue, the firm faces debt-induced collapse: the value of equity drops, the firm's default probability and bankruptcy costs jump up.

The dashed line in each panel of Figure 3 shows the benefit to shareholders of issuing a unit of new CoCos within the no-collapse region of debt levels. The benefit is lower on the right in the presence of a conversion friction. Whereas the incentive for debt substitution decreases with asset value, the incentive for issuing new CoCos increases with asset value. For completeness the figures also include the impact of replacing some equity with CoCos, which is roughly parallel to the effect of issuing new CoCos.

\subsection{The Bail-In Case}

Figure 4 illustrates the same comparisons made in the left panel of Figure 3, but now for the bail-in case. The main observation is that the incentive (for shareholders) to issue convertible debt is greater in Figure 4 than in Figure 3. This is primarily due to the lowering of the conversion threshold - the trigger is 75 in Figure 3 whereas the bail-in point is a bit below 70 in Figure 4. As long as conversion occurs before bankruptcy, the level of the conversion threshold has no effect on firm value or the value of straight debt. It does affect how value is apportioned between equity holders and CoCo investors.

\section{Debt Overhang and Investment Incentives}

In most capital structure models, equity holders are least motivated to invest in a firm precisely when the firm most needs additional equity. For a firm near bankruptcy, much of the value of an additional equity investment is captured by debt holders as the additional equity increases the market value of the debt by reducing the chances of bankruptcy. This is a problem of debt overhang (Myers [27]), and it presents a significant obstacle to recapitalizing ailing banks. Duffie [9] has proposed mandatory rights offerings as a mechanism to compel investment. Here we examine the effect of CoCos on investment incentives. 
The phenomenon of debt overhang is easiest to see in a static model, viewing equity as a call option on the assets of a firm with a strike price equal to the face value of debt, as in Merton [25]. At a low asset value, where the option is deep out-of-the-money, the option delta is close to zero: a unit increase in asset value produces much less than a unit increase in option value, so equity holders have no incentive to invest. Indeed, in this static model, the net benefit of investment is always negative.

At least three features distinguish our setting from the simple static model. First, the reduction in rollover costs that follows from safer debt means that equity holders have the potential to derive some benefit from an increase in their investment. Second, the dilutive effects of CoCo conversion creates an incentive for shareholders to invest to prevent conversion. Third, if CoCo coupons are tax deductible, shareholders have an added incentive to invest in the firm near the conversion trigger to avoid the loss of this tax benefit.

Figure 5 shows the cost to equity holders of an additional investment of 1 in various scenarios. Negative costs are benefits. For this example, we use the longer maturities for debt in Table 5, as the overhang problem is more acute in this case. This is illustrated by the solid black line in the left panel, which shows the overhang cost is positive throughout the range of asset values displayed.

The solid blue line and the dashed line show the overhang cost after the firm has issued CoCos. The blue line corresponds to replacing equity with CoCos, and the dashed line corre-

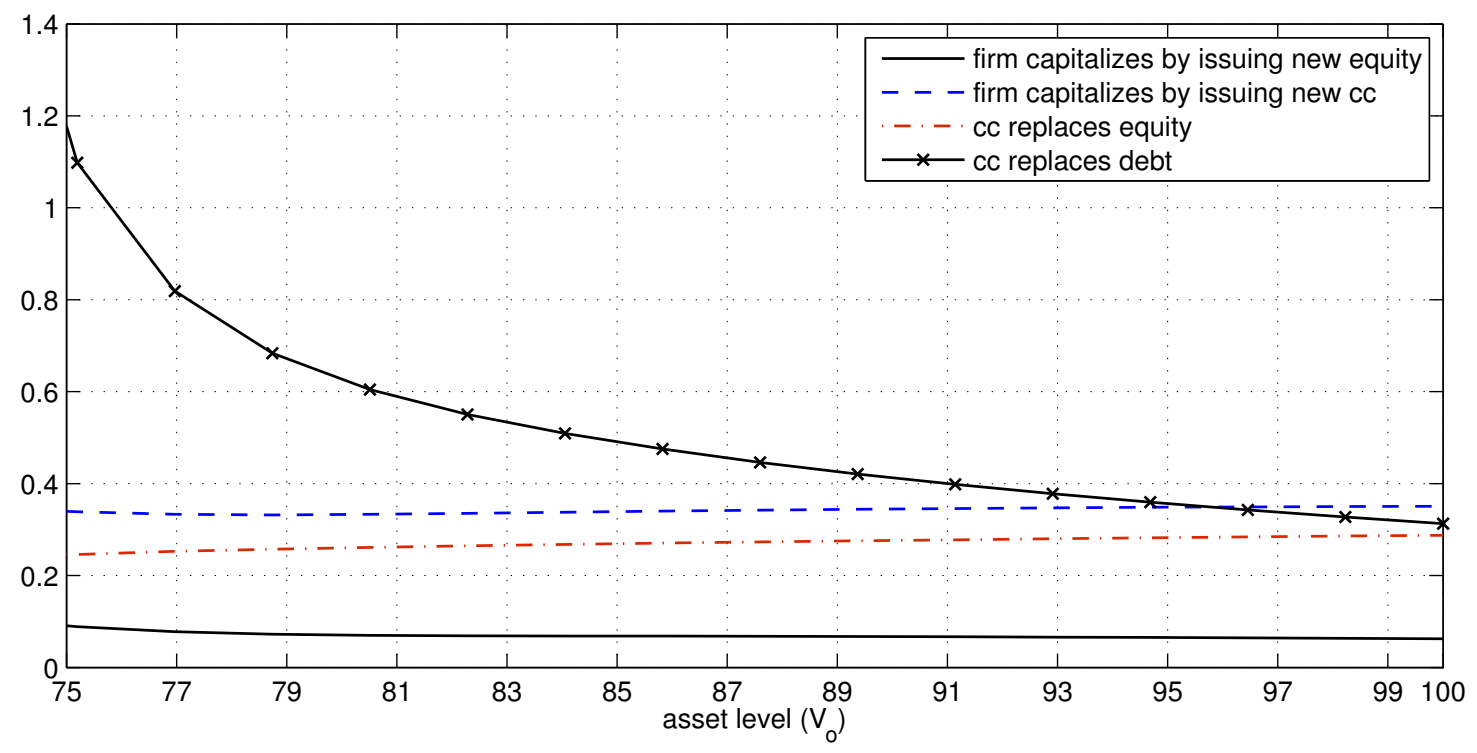

Figure 4: Change in equity value resulting from changes in capital structure with bail-in debt. 

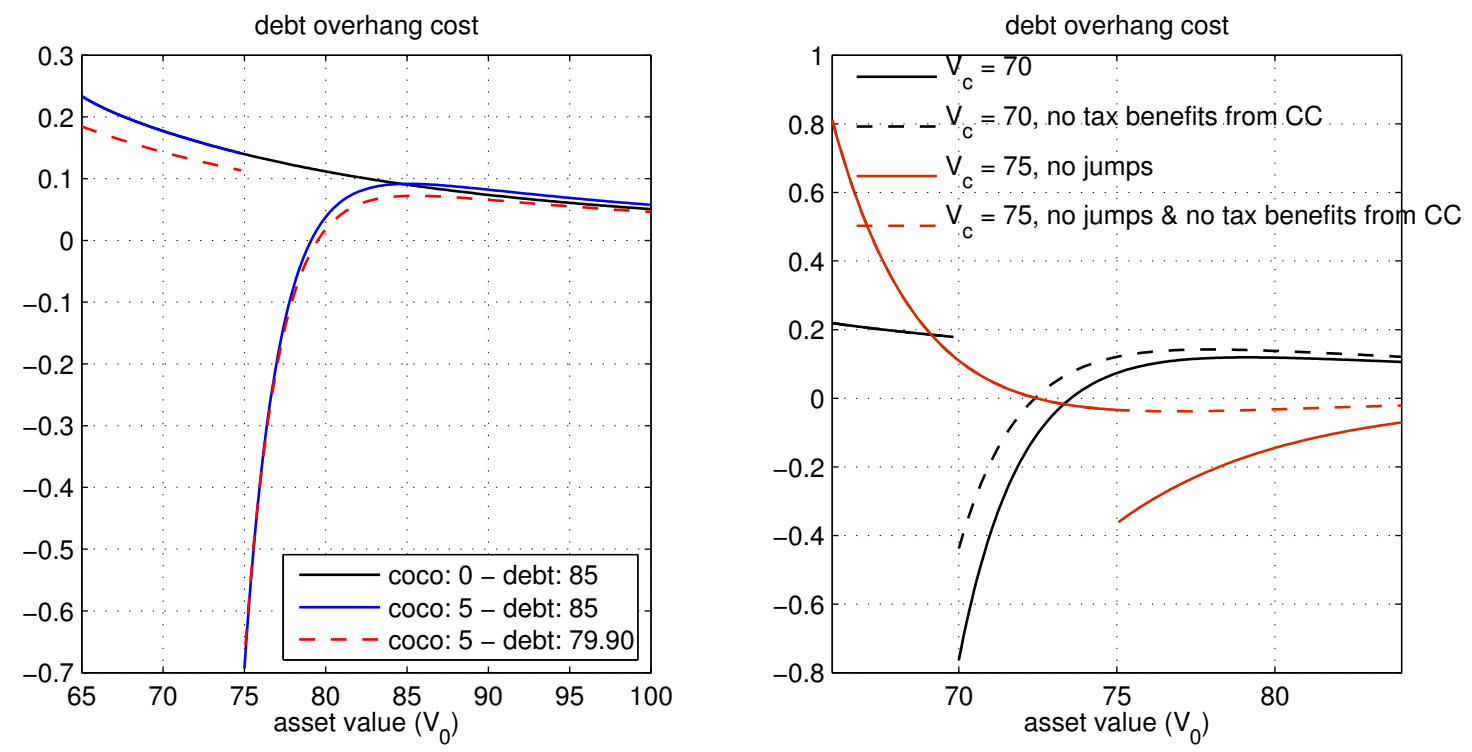

Figure 5: Net cost to shareholders of increasing the firm's asset by 1 . Negative costs are gains. The figures show that CoCos and tail risk create a strong incentive for additional investment by equity holders near the conversion trigger.

sponds to replacing straight debt with CoCos. As we move from right to left, tracing a decline in asset value toward the conversion threshold $V_{c}=75$, we see a dramatic increase in the benefit (negative cost) to equity holders of an additional investment. In other words, the presence of CoCos creates a strong incentive for equity holders to invest in the firm to avoid conversion. After conversion (below an asset level of 75), the overhang cost reverts to its level in a firm without CoCos.

The right panel of Figure 5 provides further insight into the investment incentive illustrated in the left panel. If we lower the conversion trigger from 75 to 70 , we see from the solid black line that the investment incentive becomes greatest at 70, as expected, where it is a bit greater than the greatest value in the left figure. Removing the tax-deductibility of CoCo coupons yields the dashed black line, which shows that the investment incentive is reduced but not eliminated. In the solid red line, we have returned the conversion trigger to 75 but removed the jumps from the asset process. This eliminates close to half the incentive for investment, compared to the left panel. Removing both the tax shield on CoCos and jumps in asset value eliminates almost all the investment incentive, as indicated by the dashed red line.

The tax effect is immediate: the tax shield increases the value to shareholders of avoiding the conversion of CoCos and thus creates a greater incentive for investment. The jump effect requires some explanation. Recall that the conversion ratio $\Delta$ is set so that the market value of the shares into which the CoCos convert would equal the face value of the converted debt if 
conversion were to occur at an asset level of $V_{c}$. If a downward jump takes $V_{t}$ from a level above the trigger $V_{c}$ to a level below it, then conversion occurs at an asset level lower than $V_{c}$, and the market value of the equity granted to CoCo investors is less than the face value of the debt. Equity holders thus prefer conversion following a jump to conversion at the trigger; indeed, conversion right at the trigger is the worst conversion outcome for equity holders, and this creates an incentive for investment as asset value approaches the trigger. The equity holders would prefer to delay conversion and, in effect, bet on converting at a jump rather than right at the trigger. This suggests that CoCos may create an incentive for equity investors to take on further tail risk, an issue we investigate in the next section.

\section{Asset Substitution and Risk Sensitivity}

We reviewed the problem of debt overhang in the previous section in Merton's [25] model, which views equity as a call option on the firm's assets. The same model predicts that equity value increases with the volatility of the firm's assets, giving equity holders an incentive to increase the riskiness of the firm's investments after they have secured funding from creditors. In this section, we examine this phenomenon in our dynamic model, focusing on how CoCos change the incentives. 6

We can summarize our main observations as follows. Because of the need to roll maturing debt, equity holders do not necessarily prefer more volatile assets in a dynamic model; longer debt maturity makes riskier assets more attractive to equity holders. Even when equity value does increase with asset volatility, CoCos can mitigate or entirely offset this effect, in part because equity holders are motivated to avoid conversion. In some cases, CoCos can make tail risk more attractive to equity holders even while making diffusive risk less attractive.

To illustrate these points, we start with the lower panel of Figure 6, which shows the sensitivity of equity to diffusive volatility as a function of asset value. The solid black line corresponds to a firm with no contingent capital - the sensitivity of equity to $\sigma$ is positive throughout the range and peaks just above the default barrier. As the firm nears bankruptcy, the equity holders are motivated to take on extra risk in a last-ditch effort at recovery.

We see a very different pattern in the two blue lines, corresponding to a firm in which some straight debt has been replaced with CoCos, and the two red lines, based on replacing some equity with CoCos. In both cases, the solid line is based on a conversion trigger of 85, and the

\footnotetext{
${ }^{6}$ Related questions of risk-shifting incentives are studied in Albul et al. [1], Hilscher and Raviv [16], Koziol and Lawrenz [20], and Pennacchi [30] with contingent capital and in Bhanot and Mello [2] for debt with rating triggers. Morellec [26] studies a related question of the impact of asset liquidity on debt capacity.
} 
dashed line uses a trigger of 70. This gives us four combinations of capital structure and trigger level. In all four, the sensitivity is negative at high asset values and turns sharply negative as asset value decreases toward the conversion boundary before becoming slightly positive just above the trigger, where equity holders would prefer to gamble to avoid conversion. After conversion, the pattern naturally follows that of a firm without CoCos. The key implication of the figure is that CoCos decrease, and even reverse, the incentive for the shareholders to increase the riskiness of the firm's assets.
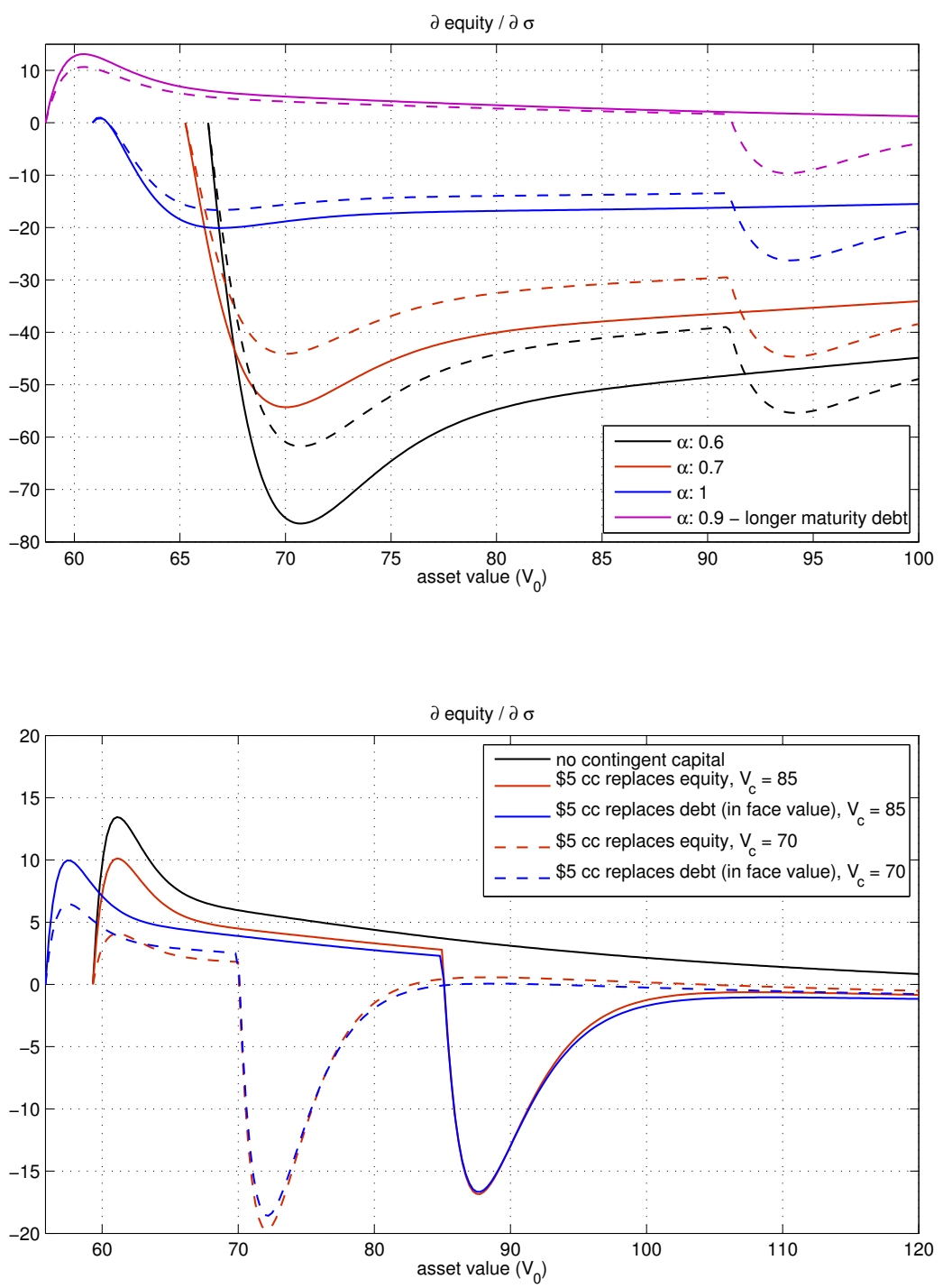

Figure 6: Sensitivity of equity value to diffusive volatility $\sigma$. With longer maturity debt, equity holders have a positive risk-shifting incentive. CoCos tend to reverse this incentive.

The top half of Figure 6 illustrates the effect of debt maturity and bankruptcy costs on the risk-shifting incentive. In each pair of lines, the dashed line has the same level of straight 
debt as the solid line but it also has CoCos. Considering first the solid lines, we see that with long-maturity debt, the risk-shifting incentive is positive, even at a rather high recovery rate of $\alpha=90 \%$. In contrast, with shorter maturity debt, the sensitivity is nearly always negative, even with a recovery rate of $100 \%$ - i.e., with no bankruptcy costs. Thus, debt maturity and not bankruptcy cost is the main driver of the sign of the risk-sensitivity. CoCos therefore have a greater effect on the risk-shifting incentive when the rest of the firm's debt has longer average maturity. The impact of CoCos is not very sensitive to the recovery rate $\alpha$.

Figures 7 and 8 illustrate similar comparisons but with the sensitivity at each asset level normalized by the value of equity at that asset level; we interpret this as measuring the risk-shifting incentive per dollar of equity. Also, the figures compare sensitivities to diffusive volatility on the left with sensitivity to tail risk, as measured by $1 / \eta_{f}$, on the right. Figure 8 uses a longer average maturity of debt than Figure 7.

The left panels of Figures 7 and 8 are consistent with what we saw in Figure 6 for the unnormalized sensitivities: with longer maturity debt, CoCos reverse the risk-shifting incentive; with shorter maturity debt, equity holders already have an incentive to reduce risk, particularly at low asset values, and CoCos make the risk sensitivity more negative.

The right panels add new information by showing sensitivity to tail risk. In both Figures 7 and 8, equity holders have a positive incentive to add tail risk, particularly with long maturity debt, but also with short maturity debt at low asset levels. Indeed, the incentive becomes very large in both cases as asset value falls. Increasing the size of the firm's balance sheet by adding CoCos leads to a modest increase in this incentive above the conversion trigger. Replacing some straight debt with CoCos reduces the incentive to take on tail risk but does not reverse it. Related comparisons are examined in Albul et al. [1] and Pennacchi [30]. Pennacchi's [30] conclusions appear to be consistent with ours, though modeling differences make a direct comparison difficult; the conclusions in Albul et al. [1] are quite different, given the absence of jumps and debt rollover in their framework.

The patterns in our results can be understood, in part, from the asset dynamics in (2.2); in particular, whereas the diffusive volatility $\sigma$ plays no role in the (risk-neutral) drift, increasing the mean jump size increases the drift. In effect, the firm earns a higher continuous yield on its assets by taking on greater tail risk. This has the potential to generate additional dividends for shareholders, though the additional yield needs to be balanced against increased rollover costs resulting from increased default risk. In addition to generating a higher yield, jump risk is attractive to shareholders because the cost of conversion is lower if it takes place at a lower asset value than at the conversion trigger. Moreover, shareholders are indifferent between bankruptcy 

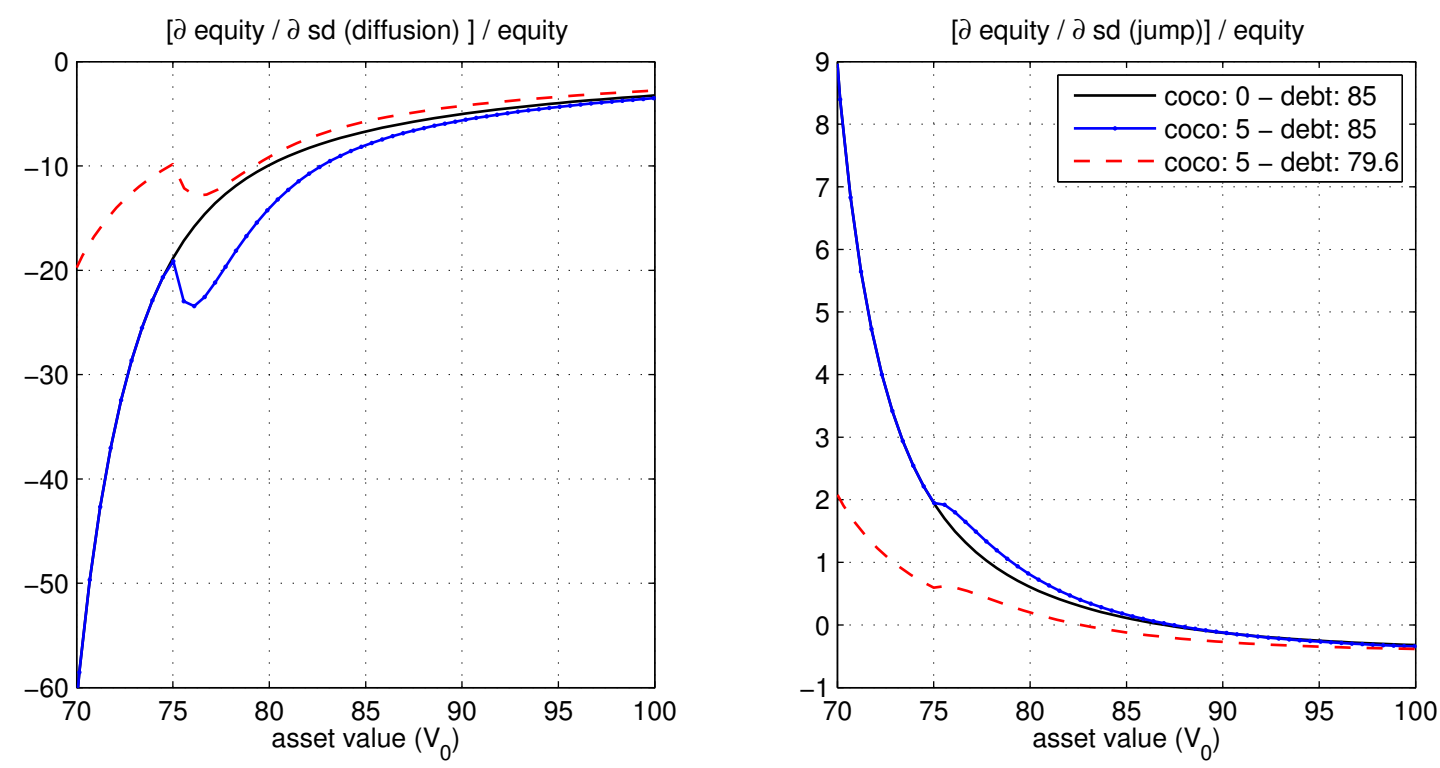

Figure 7: Sensitivity of equity value to diffusive volatility and jump risk in assets.
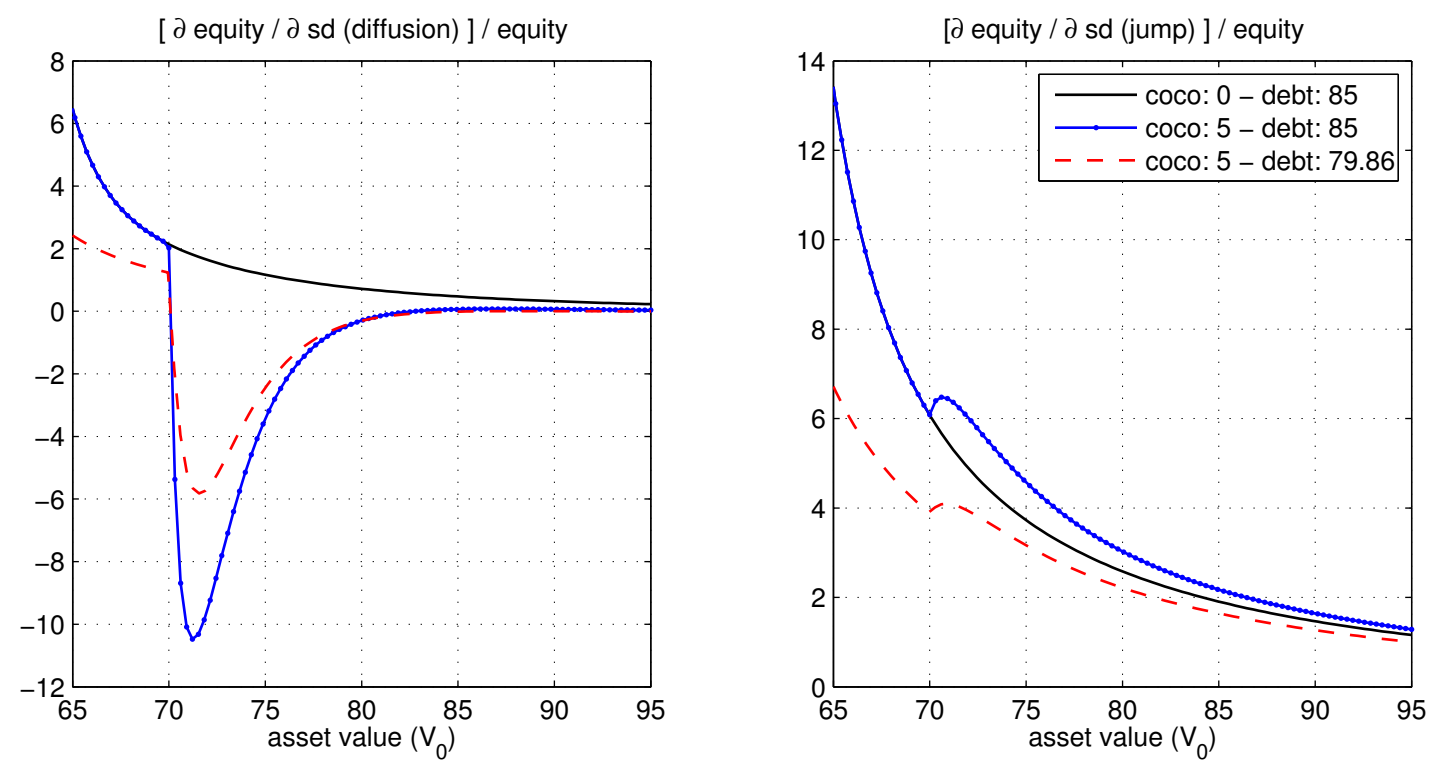

Figure 8: Same comparisons as Figure 7 but with longer average maturity. In all plots, at the same asset level the dashed line corresponds to a larger distance to default due to less outstanding regular debt. 
at an asset value below their default barrier or right at their barrier, so they are motivated to earn the higher yield from tail risk without bearing all of the downside consequences.

\section{Calibration to Bank Data Through the Crisis}

In this section, we calibrate our model to specific banks. We focus on the years leading up to and during the financial crisis, with the objective of gauging what impact CoCos might have had, had they been issued in advance of the crisis. We examine the increase in the banks' ability to absorb losses, relative to the amount of straight debt replaced with CoCos, and we calculate the reduction in debt overhang costs as an indication of whether CoCos would have created greater incentives for equity holders to inject private capital at various points in time.

As candidates for our calibration, we chose the 19 bank holding companies (the largest 19 at the time) that underwent the Supervisory Capital Assessment Program (SCAP) in 2009. From this list, we removed MetLife because banking is a small part of its overall business, and we removed GMAC (now Ally) because it is privately held. The banks are listed in Table 2, in order of asset value in 2009 .

We obtain quarterly balance sheet information from each bank holding company's quarterly 10-Q/10-K S.E.C. filings from 2004 through the third quarter of 2011, except in the case of American Express, for which we begin in 2006 because of a large spin-off in 2005. Several of the firms became bank holding companies late in our time window, so Y-9 reports would not be available throughout the period. Also, the Y-9 reports contain less information about debt maturities and interest expenses than the quarterly reports. We group all debt into three categories - deposits, short-term debt, and long-term debt — in this order of seniority. We do not separate subordinated debt from other long-term debt because of difficulties in doing so consistently and reliably. The distinction would not have much effect on our calculations. We calculate average debt maturity within each category using information provided in annual reports. We calculate total dividends and interest payments to get a total payout rate.

We linearly interpolate values within each quarter, using values from the beginning of the quarter and the beginning of the subsequent quarter; this gives us values at a weekly frequency and avoids abrupt changes at the end of each quarter. For debt maturities, we interpolate between annual reports.

Our model is driven by asset value, but asset value is not observable. So, we fit our model using balance sheet and market information and then use the model to infer asset value or a model-defined proxy for asset value. In more detail, at each week we use the linearly interpolated values to determine the bank's debt profile, dividends, and interest. As the risk-free rate, we 
use the Treasury yield corresponding to the weighted average maturity of each bank's debt.

Jump parameters are difficult to estimate, particularly for rare jumps as contemplated by our model. For the calibrations, we limit the model to a single type of jump and choose from a finite set of values for the jump rate $\lambda$ and the mean jump size $1 / \eta$. For each $(\lambda, \eta)$, we calibrate a value for the diffusive volatility $\sigma$ iteratively as follows. Given a starting value for $\sigma$, we can numerically invert our model's formula for equity at each point in time (using the market value of equity at each point in time) to get an implied market value for the assets. We then calculate the annualized sample standard deviation of the implied asset log returns, excluding returns of magnitude greater than $3.3 \sigma$, which we treat as jumps, and compare it with $\sigma$. We adjust $\sigma$ up or down depending on whether the standard deviation is larger or smaller than $\sigma$, proceeding iteratively until the values match. At that point, we have found a path of underlying assets that reproduces the market value of equity with an internally consistent level of asset volatility, for a fixed $(\lambda, \eta)$.

We repeat this procedure over a grid of $(\lambda, \eta)$ values. We limit $\lambda$ to 0.1 or 0.3 ; for $\eta$, we consider integer values between 5 and 10, but if the best fit occurs at the boundary we extend the range to ensure that does not improve the fit. We choose from the set of $(\lambda, \eta, \sigma)$ values by comparing model implied debt prices with market data of traded debt from the Fixed Income Securities Database and TRACE databases. We add up the total principal of traded debt and total market price paid in those transactions. Their ratio gives an average discount rate that the market applies to the debt. We calculate the corresponding model implied average discount for each $(\lambda, \eta, \sigma)$ using quarterly balance sheet data for the principal of debt outstanding and the model implied prices. The interest payments are already matched through our choice of coupon rates, so we choose the $(\lambda, \eta, \sigma)$ that comes closest to matching the discount on the principal as our calibrated parameters. The parameters for the 17 banks are reported in Table 2.

Given the path of asset value and all the other model parameters, we can calculate modelimplied quantities. As a first step, we calculate the endogenous bankruptcy level $V_{b}^{*}$ based on the bank's debt profile at each point in time. We can also undertake a counterfactual experiment in which part of the debt is replaced with CoCos and recalculate the default boundary. We take CoCos to be $10 \%$ of total debt, keeping the relative proportions of other types of debt unchanged. Recall that the default boundary does not depend on the CoCo conversion trigger or conversion ratio, as long as the trigger is above the default boundary, so we do not need to specify values for these features to determine $V_{b}^{*}$. In other words, we assume that the conversion trigger is set to prevent debt-induced collapse.

Table 3 provides more detailed information at four points in time. Under each date, the 


\begin{tabular}{l|ccc|cc}
\hline & \multicolumn{3}{|c|}{ Parameters } & \multicolumn{2}{c}{ Conversion Date } \\
Bank Holding Company & $\lambda$ & $\eta$ & $\sigma$ & $50 \%$ & $75 \%$ \\
\hline Bank of America Corp & 0.1 & 5 & $4.1 \%$ & Jan-09 & \\
JPMorgan Chase \& Co. & 0.1 & 8 & $4.4 \%$ & & \\
Citigroup Inc. & 0.1 & 9 & $3.9 \%$ & Nov-08 & \\
Wells Fargo \& Company & 0.1 & 5 & $4.7 \%$ & & \\
Goldman Sachs Group, Inc. & 0.1 & 5 & $3.8 \%$ & Nov-08 & \\
Morgan Stanley & 0.1 & 8 & $4.2 \%$ & Sep-08 & Dec-08 \\
PNC Financial Services & 0.3 & 8 & $7.0 \%$ & Nov-08 & Jan-09 \\
U.S. Bancorp & 0.3 & 5 & $5.5 \%$ & Jan-09 & \\
Bank of New York Mellon Corp. & 0.3 & 6 & $7.3 \%$ & Oct-08 & \\
SunTrust Banks, Inc. & 0.3 & 9 & $4.1 \%$ & Apr-08 & Jan-09 \\
Capital One Financial Corp. & 0.3 & 7 & $7.9 \%$ & Jun-08 & Jan-09 \\
BB\&T Corporation & 0.3 & 6 & $5.3 \%$ & Jun-08 & \\
Regions Financial Corporation & 0.3 & 8 & $4.7 \%$ & Jun-08 & Jan-09 \\
State Street Corporation & 0.3 & 5 & $7.4 \%$ & Oct-08 & \\
American Express Company & 0.3 & 8 & $8.6 \%$ & & \\
Fifth Third Bancorp & 0.3 & 5 & $6.3 \%$ & Jan-08 & Jun-08 \\
KeyCorp & 0.3 & 8 & $4.2 \%$ & Nov-07 & Nov-08 \\
\hline
\end{tabular}

Table 2: The table shows the calibrated parameter values $(\lambda, \eta, \sigma)$ for each bank holding company. The last two columns show the months in which CoCo conversion would have been triggered, according to the calibration, assuming CoCos made up 10\% of debt. The 50\% and $75 \%$ dilution ratios correspond to higher and lower triggers, respectively. 


\begin{tabular}{l|cc|cc|cc|cc} 
& \multicolumn{2}{|c|}{ Jan-2006 } & \multicolumn{2}{|c|}{ Jan-2007 } & \multicolumn{2}{|c|}{ Jan-2008 } & \multicolumn{2}{c}{ Jan-2009 } \\
\hline Bank of America Corp & 1.47 & $7 \%$ & 1.43 & $8 \%$ & 1.63 & $5 \%$ & 1.54 & $3 \%$ \\
JPMorgan Chase \& Co. & 1.29 & $6 \%$ & 1.29 & $6 \%$ & 1.49 & $5 \%$ & 1.50 & $5 \%$ \\
Citigroup Inc. & 1.34 & $7 \%$ & 1.32 & $6 \%$ & 1.42 & $4 \%$ & - & $2 \%$ \\
Wells Fargo \& Company & 1.11 & $19 \%$ & 1.06 & $22 \%$ & 1.44 & $9 \%$ & 1.60 & $5 \%$ \\
Goldman Sachs Group, Inc. & 1.35 & $4 \%$ & 1.41 & $5 \%$ & 1.52 & $4 \%$ & - & $4 \%$ \\
Morgan Stanley & 1.43 & $4 \%$ & 1.38 & $4 \%$ & 1.50 & $5 \%$ & - & $5 \%$ \\
PNC Financial Services & 1.17 & $19 \%$ & 1.11 & $21 \%$ & 1.29 & $14 \%$ & - & $8 \%$ \\
U.S. Bancorp & 0.95 & $32 \%$ & 0.98 & $32 \%$ & 1.11 & $24 \%$ & 1.17 & $18 \%$ \\
Bank of New York Mellon & 1.15 & $24 \%$ & 1.06 & $28 \%$ & 1.04 & $28 \%$ & 0.80 & $17 \%$ \\
SunTrust Banks, Inc. & 0.91 & $21 \%$ & 0.87 & $22 \%$ & 0.91 & $16 \%$ & - & $8 \%$ \\
Capital One Financial Corp. & 0.93 & $29 \%$ & 0.92 & $26 \%$ & 0.97 & $16 \%$ & - & $12 \%$ \\
BB\&T Corporation & 1.03 & $25 \%$ & 1.03 & $23 \%$ & 0.97 & $14 \%$ & - & $9 \%$ \\
Regions Financial Corp. & 0.90 & $24 \%$ & 0.89 & $19 \%$ & 0.87 & $12 \%$ & - & $4 \%$ \\
State Street Corporation & 1.33 & $18 \%$ & 1.25 & $20 \%$ & 1.07 & $24 \%$ & - & $11 \%$ \\
American Express Company & 1.15 & $38 \%$ & 1.13 & $36 \%$ & 1.26 & $28 \%$ & 1.50 & $18 \%$ \\
Fifth Third Bancorp & 0.89 & $26 \%$ & 0.77 & $31 \%$ & - & $17 \%$ & - & $6 \%$ \\
KeyCorp & 1.11 & $17 \%$ & 1.01 & $20 \%$ & - & $10 \%$ & - & $5 \%$ \\
\hline \hline mean & 1.15 & $18.81 \%$ & 1.11 & $19.23 \%$ & 1.23 & $13.73 \%$ & 1.35 & $8.15 \%$ \\
median & 1.15 & $19.32 \%$ & 1.06 & $20.52 \%$ & 1.26 & $13.80 \%$ & 1.50 & $5.81 \%$ \\
\hline
\end{tabular}

Table 3: Under each date the left column shows the ratio of the increase in loss absorption (the change in the default boundary after CoCo issuance) to CoCo size (as measured by market value). The right column is the distance to default (without CoCos) as a percentage of asset level. The dilution ratio is $50 \%$.

value on the left is the ratio of increased loss absorption to the market value of CoCos, where the increased loss absorption is the change in the default barrier resulting from the CoCos. A ratio of 1 indicates that a dollar of CoCos absorbs a dollar of additional losses; a ratio greater or smaller than 1 indicates a greater or smaller degree of loss absorption. The second entry under each date is the distance to default as a percentage of asset value. Comparing a single institution at different points in time, the pattern that emerges is that the loss absorption ratio tends to be greater when the firm is closer to default. The pattern does not hold across institutions because there are too many other differences in their balance sheets besides the distance to default.

The design and market value of the CoCos depends on two contractual features, the trigger $V_{c}$ and the conversion price $\Delta$. By the definition of $\Delta$, the fraction of total equity held by CoCo investors just after conversion is $\Delta P_{2} /\left(1+\Delta P_{2}\right)$, where $P_{2}$ is the face value of CoCos issued. We choose $\Delta$ so that this ratio is either $50 \%$ or $75 \%$, and we refer to this as the dilution ratio. We then set the conversion level $V_{c}$ so that if conversion were to occur exactly at $V_{t}=V_{c}$, the 
market value of the equity CoCo investors would receive would equal the face value $P_{2}$ of the CoCos: conversion at $V_{t}=V_{c}$ implies neither a premium nor a discount. In order that the equity value received be equal to $P_{2}$ at both $50 \%$ and $75 \%$ dilution ratios, the higher dilution ratio must coincide with a lower conversion trigger. The results in Table 3 are based on a $50 \%$ dilution ratio, but the corresponding results with $75 \%$ dilution are virtually identical.

The last two columns of Table 2 report the month in which the model calibrations predict each of the banks would have triggered conversion of CoCos with a high trigger (50\% dilution ratio) and a low trigger ( $75 \%$ dilution ratio). In each case, the CoCo size is equal to $10 \%$ of the bank's total debt. The calibrations predict that all the banks except JPMorgan Chase, Wells Fargo, and American Express would have crossed the high conversion trigger sometime between November 2007 and January 2009; seven of the banks would have crossed the lower conversion trigger as well.

Next, we consider debt overhang costs. For each bank in each week, we calculate the size of the equity investment required to increase assets by $1 \%$. From this we subtract the net increase in equity value, which we calculate by taking the value of equity just after the investment (as calculated by the model) and subtracting the value of equity just before the investment (as observed in the data). This is our measure of debt overhang cost: if it is positive, it measures how much less equity holders get from their investment than they put in. A negative cost indicates a net benefit to investment.

Table 4 presents more detailed information at three dates prior to key points in the financial crisis: one month before the announcement of JP Morgan's acquisition of Bear Stearns; one month before final approval of the acquisition; and one month before the Lehman bankruptcy. For each date, the table shows the debt overhang cost without CoCos and with high-trigger CoCos; the third column under each date shows the distance to the conversion boundary as a percentage of asset value. Interestingly, several of the largest banks show significantly negative debt overhang costs even without CoCos. Recall from Section 6 that this is possible in a model with debt rollover, though not with a single (finite or infinite) debt maturity. Greater asset value implies greater bankruptcy costs and reducing these costs may partly explain the motivation for shareholders to increase their investments in the largest firms. Also, if the market perceives a too-big-to-fail guarantee for the largest banks that is absent from our model, then the model's shareholders may see the largest banks as overly leveraged relative to the market's perception.

We focus on comparisons between columns of the table - a single firm under different conditions - rather than comparisons across rows. With few exceptions, the effect of the CoCos is to lower the debt overhang cost, and the impact is often substantial. The effect 


\begin{tabular}{l|ccc|ccc|ccc} 
& \multicolumn{3}{|c|}{ Feb-2008 } & \multicolumn{3}{c}{ Apr-2008 } & \multicolumn{3}{c}{ Aug-2008 } \\
\hline Bank of America Corp & $-29 \%$ & $-32 \%$ & $6 \%$ & $-26 \%$ & $-30 \%$ & $5 \%$ & $-28 \%$ & $-42 \%$ & $3 \%$ \\
JPMorgan Chase \& Co. & $-75 \%$ & $-51 \%$ & $5 \%$ & $-43 \%$ & $-41 \%$ & $5 \%$ & $-93 \%$ & $-60 \%$ & $3 \%$ \\
Citigroup Inc. & $-42 \%$ & $-53 \%$ & $3 \%$ & $-24 \%$ & $-45 \%$ & $2 \%$ & $-54 \%$ & $-65 \%$ & $2 \%$ \\
Wells Fargo \& Company & $-35 \%$ & $-23 \%$ & $8 \%$ & $-33 \%$ & $-20 \%$ & $8 \%$ & $-33 \%$ & $-21 \%$ & $7 \%$ \\
Goldman Sachs Group & $-51 \%$ & $-45 \%$ & $2 \%$ & $-33 \%$ & $-42 \%$ & $2 \%$ & $-53 \%$ & $-54 \%$ & $2 \%$ \\
Morgan Stanley & $21 \%$ & $-42 \%$ & $1 \%$ & $21 \%$ & $-36 \%$ & $1 \%$ & $-20 \%$ & $-58 \%$ & $2 \%$ \\
PNC Financial Services & $-11 \%$ & $-16 \%$ & $7 \%$ & $-7 \%$ & $-12 \%$ & $8 \%$ & $-10 \%$ & $-12 \%$ & $8 \%$ \\
U.S. Bancorp & $4 \%$ & $4 \%$ & $13 \%$ & $5 \%$ & $5 \%$ & $13 \%$ & $5 \%$ & $5 \%$ & $11 \%$ \\
Bank of New York Mellon & $-3 \%$ & $-2 \%$ & $17 \%$ & $-1 \%$ & $0 \%$ & $14 \%$ & $6 \%$ & $4 \%$ & $8 \%$ \\
SunTrust Banks, Inc. & $-2 \%$ & $-20 \%$ & $2 \%$ & $5 \%$ & - & - & $9 \%$ & - & - \\
Capital One Financial & $-4 \%$ & $-28 \%$ & $3 \%$ & $4 \%$ & $-34 \%$ & $2 \%$ & $6 \%$ & - & - \\
BB\&T Corporation & $2 \%$ & $-11 \%$ & $4 \%$ & $4 \%$ & $-12 \%$ & $4 \%$ & $6 \%$ & $-60 \%$ & $1 \%$ \\
Regions Financial Corp. & $-7 \%$ & $-24 \%$ & $3 \%$ & $-8 \%$ & $-42 \%$ & $2 \%$ & $-9 \%$ & - & - \\
State Street Corporation & $2 \%$ & $2 \%$ & $11 \%$ & $5 \%$ & $-1 \%$ & $6 \%$ & $0 \%$ & $-11 \%$ & $5 \%$ \\
American Express Co. & $-12 \%$ & $-13 \%$ & $20 \%$ & $-7 \%$ & $-10 \%$ & $20 \%$ & $-10 \%$ & $-12 \%$ & $17 \%$ \\
Fifth Third Bancorp & $12 \%$ & $-79 \%$ & $0 \%$ & $17 \%$ & - & - & $19 \%$ & - & - \\
KeyCorp & $-6 \%$ & $-137 \%$ & $0 \%$ & $-1 \%$ & - & - & $5 \%$ & - & - \\
\hline
\end{tabular}

Table 4: Under each date, the first column is the debt overhang cost as a percentage of the increase in assets with no CoCos. The second column quotes the same value when $10 \%$ of debt is replaced with $\mathrm{CoCos}$ and $\mathrm{CoCo}$ investors receive $50 \%$ of equity at conversion. The third column is the distance to conversion as the percentage of assets. The dates correspond to one month before announcement and final approval of acquisition of Bear Stearns by JPMorgan and one month before the Lehman bankruptcy. A table entry is blank if the corresponding date is later than the CoCo conversion date for the corresponding bank.

depends on the interaction of several factors, including leverage, debt maturity, and the riskfree rate, which enters into the risk-neutral drift. The largest reductions in debt overhang cost generally coincide with a small distance to conversion, and, in most cases in which a bank draws closer to the conversion boundary over time, the resulting reduction in debt overhang cost becomes greater. The values in the table are for $50 \%$ dilution. The pattern with $75 \%$ is similar, but the decrease in the debt overhang cost is smaller in that case because the distance from the conversion trigger is greater.

The magnitudes of the quantities reported in these tables and figures are subject to the many limitations and simplifications of our model and calibration. We see these results as providing a useful additional perspective on the comparative statics of earlier sections of the paper; the directional effects and the comparisons over time should be more informative than the precise numerical values. These calibrations and our exploration of counterfactual scenarios, though hypothetical, shed light on how CoCo issuance in advance of the financial crisis might have affected loss absorption capacity, incentives for additional equity investment, and how the 
choice of conversion trigger and dilution ratio might have determined the timing of conversion.

\section{Concluding Remarks}

The key contribution of this paper lies in combining endogenous default, debt rollover, and jumps and diffusion in income and asset value to analyze the incentive effects of contingent convertibles and bail-in debt. Through debt rollover, shareholders capture some of the benefits (in the form of lower bankruptcy costs) from reduced asset riskiness and lower leverage benefits that would otherwise accrue solely to creditors. These features shape many of the incentives we consider, as do the tax treatment of CoCos and tail risk. The phenomenon of debt-induced collapse, which is observable only when CoCos are combined with endogenous default, points to the need to set the conversion trigger sufficiently high so that conversion unambiguously precedes bankruptcy. Our calibrations suggest that CoCos could have had a significant impact on the largest U.S. bank holding companies in the lead up to the financial crisis.

Our analysis does not include asymmetric information, nor does it directly incorporate agency issues; both considerations are potentially relevant to the incentives questions we investigate. Some important practical considerations, such as the size of the investor base for CoCos, the behavior of stock and bond prices near the trigger, and the complexity of these instruments are also outside the model. The analysis provided here should nevertheless help inform the discussion of the merits and potential shortcomings of CoCos and other hybrid capital instruments.

Acknowledgments. The authors thank Robert M. Anderson, Mark Flannery, Jamie MacAndrews, Suresh Sundaresan, and Zhenyu Wang for comments and helpful discussions. The authors are also grateful for comments from Alon Raviv and participants at the Cleveland Fed Capital Requirements Conference, the Chicago Fed Bank Structure Conference, the FDIC Derivatives and Risk Management Conference, the Federal Reserve Board Finance Forum, the EPFL Lausanne finance seminar, and the FMA Asia conference. The first author acknowledges financial support from the Hong Kong Research Grant Council (Grant No. 411110) and the hospitality of the Columbia University IEOR department. The fourth author acknowledges financial support from the Coleman Fung Risk Management Research Center at U.C. Berkeley. 


\section{References}

[1] Albul, B., Jaffee, D.M., and Tchistyi, A. (2010) Contingent Convertible Bonds and Capital Structure Decisions, working paper, University of California, Berkeley.

[2] Bhanot, K., and Mello, A. (2006). Should corporate debt include a rating trigger? Journal of Financial Economics 79, 1:69-98.

[3] Bolton, P., and Samama, F., (2012) Capital access bonds: contingent capital with an option to convert. Economic Policy 27, 275-317.

[4] Calomiris, C.W., and Herring, R.J. (2011) Why and How to Design a Contingent Convertible Debt Requirement. Available at SSRN: http://ssrn.com/abstract=1815406

[5] Calomiris, C. and C. Kahn (1991). The role of demandable debt in structuring optimal banking arrangements, American Economic Review 81, 497-513.

[6] Chen, N., Glasserman, P., Nouri, B., and Pelger, M. (2012) CoCos, Bail-In, and Tail Risk. Working Paper 0004, Office of Financial Research. Available at www.treasury.gov/ofr.

[7] Chen, N. and S. G. Kou. (2009). Credit spreads, optimal capital structure, and implied volatility with endogenous default and jump risk. Mathematical Finance 19, 343-378.

[8] Décamps, J., and Villeneuve, S. (2012). Rethinking dynamic capital structure models with roll-over debt. Mathematical Finance, to appear.

[9] Duffie, D. (2010) A Contractual Approach to Restructuring Financial Institutions, in G. Schultz, K. Scott, and J. Taylor, eds., Ending Government Bailouts as we Know Them.

[10] Flannery, M.J. (2005) "No Pain, No Gain?" Effecting Market Discipline via "Reverse Convertible Debentures," in H.S. Scott (ed.), Capital Adequacy Beyond Basel: Banking, Securities, and Insurance, Oxford University Press.

[11] Flannery, M.J. (2009) Stabilizing Large Financial Institutions with Contingent Capital Certificates. Available at SSRN: http://ssrn.com/abstract $=1485689$.

[12] Glasserman, P., and Nouri, B. (2012) Contingent capital with a capital-ratio trigger. Management Science 58, 1816-1833.

[13] Glasserman, P., and Nouri, B. (2012) Market-Triggered Changes in Capital Structure: Equilibrium Price Dynamics, working paper, Columbia Business School, Columbia University. 
[14] Goldstein, R., N. Ju, and H. Leland (2001): An EBIT-based model of dynamic capital structure. Journal of Business 74, 483-512.

[15] He, Z. and W. Xiong (2012). Rollover risk and credit risk, Journal of Finance 67, 391-429.

[16] Hilscher, J., and Raviv, A. (2011). Bank stability and market discipline: debt-for-equity swap versus subordinated notes. Working paper, International Business School, Brandeis University, Waltham, Mass.

[17] Himmelberg, C.P., and Tsyplakov, S. (2012) Pricing Contingent Capital Bonds: Incentives Matter, working paper, Moore School of Business, University of South Carolina.

[18] Kou, S. G. (2002). A Jump Diffusion Model for Option Pricing, Management Science 48, 1086-1101.

[19] Kou, S. G., and Wang, H. (2003). First passage times of a jump diffusion process, Advances in Applied Porbability 35, 504-531.

[20] Koziol, C., and Lawrenz, J. (2012) Contingent Convertibles: Solving or Seeding the Next Banking Crisis? Journal of Banking and Finance 36, 1:90-104.

[21] Leland, H. E. (1994). Corporate Debt Value, Bond Covenants, and Optimal Capital Structure. Journal of Finance 49, 1213-1252.

[22] Leland, H. E., and K. B. Toft (1996). Optimal Capital Structure, Endogenous Bankruptcy, and the Term Structure of Credit Spreads. Journal of Finance 51, 987-1019.

[23] Madan, D., and Schoutens, W. (2010) Conic Coconuts: The Pricing of Contingent Capital Notes Using Conic Finance. Working Paper RHS-06-135, Robert H. Smith School of Business, University of Maryland.

[24] McDonald, R. (2013) Contingent Capital with a Dual Price Trigger, Journal of Financial Stability 9, 230-241.

[25] Merton, R. C. (1974). On the Pricing of Corporate Debt: The Risk Structure of Interest Rates. Journal of Finance, 29, 449-470.

[26] Morellec, E. (2001) Asset liquidity, capital structure, and secured debt. Journal of Financial Economics 61, 173-206. 
[27] Myers, S. C. (1977) Determinants of Corporate Borrowing. Journal of Financial Economics 5, 147-175.

[28] Naik, V., and M. Lee (1990). General Equilibrium Pricing of Options on the Market Portfolio with Discontinuous Returns, Review of Financial Studies 3, 493-521.

[29] Pazarbasioglu, C., Zhou, J., Le Leslé, V., and Moore, M. (2011) Contingent Capital: Economic Rationale and Design Features, Staff Discussion Note 11/010, International Monetary Fund, Washington, D.C.

[30] Pennacchi, G. (2010) A Structural Model of Contingent Bank Capital, Federal Reserve Bank of Cleveland Working Paper 10-04.

[31] Pennacchi, G., Vermaelen, T., and Wolff, C.C.P. (2010) Contingent Capital: The Case for COERCs, working paper.

[32] Squam Lake Working Group (2009) An Expedited Resolution Mechanism for Distressed Financial Firms: Regulatory Hybrid Securities, Council on Foreign Relations.

[33] Sundaresan, S., and Z. Wang. (2010). Design of contingent capital with a stock price trigger for conversion, working paper.

\section{A Proofs for Section 2}

\section{A.1 Optimal Default Barrier Without CoCos}

Chen and Kou [7] have shown that for a firm with only straight debt $P_{1}$, the optimal default barrier is $V_{b}^{\mathrm{PC}}=P_{1} \epsilon_{1}$, with with

$$
\epsilon_{1}=\frac{\frac{c_{1}+m}{r+m} \gamma_{1, r+m} \gamma_{2, r+m}-\frac{\kappa c_{1}}{r} \gamma_{1, r} \gamma_{2, r}}{(1-\alpha)\left(\gamma_{1, r}+1\right)\left(\gamma_{2, r}+1\right)+\alpha\left(\gamma_{1, r+m}+1\right)\left(\gamma_{2, r+m}+1\right)} \frac{\eta+1}{\eta} .
$$

where $-\gamma_{1, \rho}>-\eta>-\gamma_{2, \rho}$ are the two negative roots of the equation

$$
G(x)=\left(r-\delta-\frac{1}{2} \sigma^{2}-\lambda\left(\frac{\eta}{\eta+1}-1\right)\right)+\frac{1}{2} \sigma^{2} x^{2}+\lambda\left(\frac{\eta}{\eta+x}-1\right)=\rho .
$$

A similar argument shows that the constant $\epsilon_{2}$ that we need for $V_{b}^{\mathrm{NC}}$ is given by

$$
\epsilon_{2}=\frac{\frac{c_{2}+m}{r+m} \gamma_{1, r+m} \gamma_{2, r+m}-\frac{\kappa c_{2}}{r} \gamma_{1, r} \gamma_{2, r}}{(1-\alpha)\left(\gamma_{1, r}+1\right)\left(\gamma_{2, r}+1\right)+\alpha\left(\gamma_{1, r+m}+1\right)\left(\gamma_{2, r+m}+1\right)} \frac{\eta+1}{\eta} .
$$




\section{A.2 Proof of Theorem 1}

We will use the following lemma:

Lemma 1. If $V_{b}^{P C} \leq V_{c} \leq V_{b}^{N C}$ and $E^{B C}\left(V ; V_{b}^{P C}\right) \geq 0$ for all $V \in\left(V_{c}, V_{b}^{N C}\right)$, then $E^{B C}\left(V ; V_{b}^{P C}\right) \geq$ $E^{N C}\left(V ; V_{b}^{N C}\right) \geq 0$ for all $V$.

Proof of Lemma 1. For $V \leq V_{c}$, we have $E^{\mathrm{BC}}\left(V ; V_{b}^{\mathrm{PC}}\right)=E^{\mathrm{PC}}\left(V ; V_{b}^{\mathrm{PC}}\right)$, by definition, and $E^{\mathrm{PC}}\left(V ; V_{b}^{\mathrm{PC}}\right) \geq 0$ because $V_{b}^{\mathrm{PC}}$ is the optimal default barrier for the post-conversion firm and thus preserves limited liability for the post-conversion firm. Combining this with the hypothesis in the lemma yields $E^{\mathrm{BC}}\left(V ; V_{b}^{\mathrm{PC}}\right) \geq 0$ for all $V \leq V_{b}^{\mathrm{NC}}$. But for $V \leq V_{b}^{\mathrm{NC}}, E^{\mathrm{NC}}\left(V ; V_{b}^{\mathrm{NC}}\right)=0$, so the conclusion of the lemma holds for all $V \leq V_{b}^{\mathrm{NC}}$.

Now consider $V>V_{b}^{\mathrm{NC}}$. The value of equity before conversion is the difference between firm value and debt value and is given explicitly by

$$
\begin{aligned}
E^{\mathrm{BC}}\left(V ; V_{b}^{\mathrm{PC}}\right)= & V-(1-\alpha) \mathbb{E}^{\mathrm{Q}}\left[V_{\tau_{b}} e^{-r \tau_{b}}\right] \\
& +\frac{P_{1} \kappa c_{1}}{r} \mathbb{E}^{\mathrm{Q}}\left[1-e^{-r \tau_{b}}\right]+\frac{P_{2} \kappa c_{2}}{r} \mathbb{E}^{\mathrm{Q}}\left[1-e^{-r \tau_{c}}\right] \\
& -P_{1}\left(\frac{c_{1}+m}{r+m}\right) \mathbb{E}^{\mathrm{Q}}\left[1-e^{-(r+m) \tau_{b}}\right]-P_{2}\left(\frac{c_{2}+m}{r+m}\right) \mathbb{E}^{\mathrm{Q}}\left[1-e^{-(r+m) \tau_{c}}\right] \\
& -\alpha \mathbb{E}^{\mathrm{Q}}\left[V_{\tau_{b}} e^{-(r+m) \tau_{b}}\right]-\frac{\Delta P_{2}}{1+\Delta P_{2}} \mathbb{E}^{\mathrm{Q}}\left[e^{-(r+m) \tau_{c}} E^{\mathrm{PC}}\left(V_{\tau_{c}} ; V_{b}^{\mathrm{PC}}\right)\right] .
\end{aligned}
$$

Similarly, if we let $\tau_{b}^{\mathrm{NC}}$ denote the first time $V$ is at or below $V_{b}^{\mathrm{NC}}$, we have

$$
\begin{aligned}
E^{\mathrm{NC}}\left(V ; V_{b}^{\mathrm{N} C}\right)= & V-(1-\alpha) \mathbb{E}^{\mathrm{Q}}\left[V_{\tau_{b}^{\mathrm{NC}}} e^{-r \tau_{b}^{\mathrm{NC}}}\right] \\
& +\frac{\kappa\left(P_{1} c_{1}+P_{2} c_{2}\right)}{r} \mathbb{E}^{\mathrm{Q}}\left[1-e^{-r \tau_{b}^{\mathrm{NC}}}\right] \\
& -\left\{P_{1}\left(\frac{c_{1}+m}{r+m}\right)+P_{2}\left(\frac{c_{2}+m}{r+m}\right)\right\} \mathbb{E}^{\mathrm{Q}}\left[1-e^{-(r+m) \tau_{b}^{\mathrm{NC}}}\right] \\
& -\alpha \mathbb{E}^{\mathrm{Q}}\left[V_{\tau_{b}^{\mathrm{NC}}} e^{-(r+m) \tau_{b}^{\mathrm{NC}}}\right] .
\end{aligned}
$$

Note the fact that that $e^{-r \tau_{b}} \leq e^{-r \tau_{b}^{\mathrm{NC}}}$ and $V_{\tau_{b}} \leq V_{\tau_{b}^{\mathrm{NC}}}$. We then have

$$
\mathbb{E}\left[\left(V_{\tau_{b}^{\mathrm{NC}}} e^{-r \tau_{b}^{\mathrm{NC}}}-V_{\tau_{b}} e^{-r \tau_{b}}\right)\left(1-e^{-m \tau_{b}^{\mathrm{NC}}}\right)\right] \geq 0 .
$$


Using this inequality and taking the difference between (A.1) and (A.2), we get

$$
\begin{aligned}
& E^{\mathrm{BC}}\left(V ; V_{b}^{\mathrm{PC}}\right)-E^{\mathrm{NC}}\left(V ; V_{b}^{\mathrm{NC}}\right) \\
& \geq \quad E^{\mathrm{BC}}\left(V ; V_{b}^{\mathrm{PC}}\right)-E^{\mathrm{NC}}\left(V ; V_{b}^{\mathrm{NC}}\right)-(1-\alpha) \mathbb{E}\left[\left(V_{\tau_{b}^{\mathrm{NC}}} e^{-r \tau_{b}^{\mathrm{NC}}}-V_{\tau_{b}} e^{-r \tau_{b}}\right)\left(1-e^{-m \tau_{b}^{\mathrm{NC}}}\right)\right] \\
&=-(1-\alpha) \mathbb{E}^{\mathrm{Q}}\left[V_{\tau_{b}} e^{-r \tau_{b}-m \tau_{b}^{\mathrm{NC}}}\right]+\mathbb{E}^{\mathrm{Q}}\left[V_{\tau_{b}^{\mathrm{NC}}} e^{-(r+m) \tau_{b}^{\mathrm{NC}}}\right] \\
& \quad+\frac{P_{1} \kappa c_{1}}{r} \mathbb{E}^{\mathrm{Q}}\left[e^{-r \tau_{b}^{\mathrm{NC}}}-e^{-r \tau_{b}}\right]+\frac{P_{2} \kappa c_{2}}{r} \mathbb{E}^{\mathrm{Q}}\left[e^{-r \tau_{b}^{\mathrm{NC}}}-e^{-r \tau_{c}}\right] \\
&-P_{1}\left(\frac{c_{1}+m}{r+m}\right) \mathbb{E}^{\mathrm{Q}}\left[e^{-(r+m) \tau_{b}^{\mathrm{NC}}}-e^{-(r+m) \tau_{b}}\right]-P_{2}\left(\frac{c_{2}+m}{r+m}\right) \mathbb{E}^{\mathrm{Q}}\left[e^{-(r+m) \tau_{b}^{\mathrm{NC}}}-e^{-(r+m) \tau_{c}}\right] \\
&-\alpha \mathbb{E}^{\mathrm{Q}}\left[V_{\tau_{b}} e^{-(r+m) \tau_{b}}\right]-\frac{\Delta P_{2}}{1+\Delta P_{2}} \mathbb{E}^{\mathrm{Q}}\left[e^{-(r+m) \tau_{c}} E^{\mathrm{PC}}\left(V_{\tau_{c}} ; V_{b}^{\mathrm{PC}}\right)\right] .
\end{aligned}
$$

On the other hand, we know that $E^{\mathrm{BC}}\left(V ; V_{b}^{\mathrm{PC}}\right) \geq 0$ for all $V \leq V_{b}^{\mathrm{NC}}$, so it follows that

$$
\mathbb{E}^{\mathrm{Q}}\left[e^{-(r+m) \tau_{b}^{\mathrm{NC}}} E^{\mathrm{B} C}\left(V_{\tau_{b}^{\mathrm{NC}}} ; V_{b}^{\mathrm{PC}}\right)\right] \geq 0
$$

Recall that the expectations here and in (A.1) and (A.2) are conditional expectations given the current time $t$ and value $V_{t}=V$, though we have suppressed the conditioning to simplify the notation. To make the conditioning explicit, let $\mathbb{E}^{\mathbb{Q}}\left[\cdot \mid V_{\tau_{b}^{\mathrm{NC}}}\right]$ denote the expectation conditioned on $V=V_{\tau_{b}^{\mathrm{NC}}}$. Substituting (A.1) for $E^{\mathrm{BC}}$, evaluated at $V=V_{\tau_{b}^{\mathrm{NC}}}$ and $t=\tau_{b}^{\mathrm{NC}}$ yields

$$
\begin{aligned}
0 \leq & \mathbb{E}^{\mathrm{Q}}\left[e^{-(r+m) \tau_{b}^{\mathrm{NC}}} V_{\tau_{b}^{\mathrm{NC}}}-e^{-(r+m) \tau_{b}^{\mathrm{NC}}}(1-\alpha) \mathbb{E}^{\mathrm{Q}}\left[V_{\tau_{b}} e^{-r\left(\tau_{b}-\tau_{b}^{\mathrm{NC}}\right)} \mid V_{\tau_{b}^{\mathrm{NC}}}\right]\right. \\
& +e^{-(r+m) \tau_{b}^{\mathrm{NC}}} \frac{P_{1} \kappa c_{1}}{r} \mathbb{E}^{\mathrm{Q}}\left[1-e^{-r\left(\tau_{b}-\tau_{b}^{\mathrm{NC}}\right)} \mid V_{\tau_{b}^{\mathrm{NC}}}\right]+e^{-(r+m) \tau_{b}^{\mathrm{NC}}} \frac{P_{2} \kappa c_{2}}{r} \mathbb{E}^{\mathrm{Q}}\left[1-e^{-r\left(\tau_{c}-\tau_{b}^{\mathrm{NC}}\right)} \mid V_{\tau_{b}^{\mathrm{NC}}}\right] \\
& -e^{-(r+m) \tau_{b}^{\mathrm{NC}}} P_{1}\left(\frac{c_{1}+m}{r+m}\right) \mathbb{E}^{\mathrm{Q}}\left[1-e^{-(r+m)\left(\tau_{b}-\tau_{b}^{\mathrm{NC}}\right)} \mid V_{\tau_{b}^{\mathrm{NC}}}\right] \\
& -e^{-(r+m) \tau_{b}^{\mathrm{NC}}} P_{2}\left(\frac{c_{2}+m}{r+m}\right) \mathbb{E}^{\mathrm{Q}}\left[1-e^{-(r+m)\left(\tau_{c}-\tau_{b}^{\mathrm{NC}}\right)} \mid V_{\tau_{b}^{\mathrm{NC}}}\right] \\
& -e^{-(r+m) \tau_{b}^{\mathrm{NC}}} \alpha \mathbb{E}^{\mathrm{Q}}\left[V_{\tau_{b}} e^{-(r+m)\left(\tau_{b}-\tau_{b}^{\mathrm{NC}}\right)} \mid V_{\tau_{b}^{\mathrm{NC}}}\right] \\
& \left.-e^{-(r+m) \tau_{b}^{\mathrm{NC}}} \frac{\Delta P_{2}}{1+\Delta P_{2}} \mathbb{E}^{\mathrm{Q}}\left[e^{-(r+m)\left(\tau_{c}-\tau_{b}^{\mathrm{NC}}\right)} E^{\mathrm{PC}}\left(V_{\tau_{c}} ; V_{b}^{\mathrm{PC}}\right) \mid V_{\tau_{b}^{\mathrm{NC}}}\right]\right]
\end{aligned}
$$

The right side of (A.4) simplifies to

$$
\begin{aligned}
& -(1-\alpha) \mathbb{E}^{\mathrm{Q}}\left[V_{\tau_{b}} e^{-r \tau_{b}-m \tau_{b}^{\mathrm{NC}}}\right]+\mathbb{E}^{\mathrm{Q}}\left[V_{\tau_{b}^{\mathrm{NC}}} e^{-(r+m) \tau_{b}^{\mathrm{NC}}}\right] \\
& +\frac{P_{1} \kappa c_{1}}{r} \mathbb{E}^{\mathrm{Q}}\left[e^{-m \tau_{b}^{\mathrm{NC}}}\left(e^{-r \tau_{b}^{\mathrm{NC}}}-e^{-r \tau_{b}}\right)\right]+\frac{P_{2} \kappa c_{2}}{r} \mathbb{E}^{\mathrm{Q}}\left[e^{-m \tau_{b}^{\mathrm{NC}}}\left(e^{-r \tau_{b}^{\mathrm{NC}}}-e^{-r \tau_{c}}\right)\right] \\
& -P_{1}\left(\frac{c_{1}+m}{r+m}\right) \mathbb{E}^{\mathrm{Q}}\left[e^{-(r+m) \tau_{b}^{\mathrm{NC}}}-e^{-(r+m) \tau_{b}}\right]-P_{2}\left(\frac{c_{2}+m}{r+m}\right) \mathbb{E}^{\mathrm{Q}}\left[e^{-(r+m) \tau_{b}^{\mathrm{NC}}}-e^{-(r+m) \tau_{c}}\right] \\
& -\alpha \mathbb{E}^{\mathrm{Q}}\left[V_{\tau_{b}} e^{-(r+m) \tau_{b}}\right]-\frac{\Delta P_{2}}{1+\Delta P_{2}} \mathbb{E}^{\mathrm{Q}}\left[e^{-(r+m) \tau_{c}} E^{\mathrm{PC}}\left(V_{\tau_{c}} ; V_{b}^{\mathrm{PC}}\right)\right],
\end{aligned}
$$


which is less than or equal to the right side of (A.3) because $e^{-m \tau_{b}^{\mathrm{NC}}} \leq 1$. We have thus shown that $E^{\mathrm{BC}}\left(V ; V_{b}^{\mathrm{PC}}\right) \geq E^{\mathrm{NC}}\left(V ; V_{b}^{\mathrm{NC}}\right) \geq 0$ for $V>V_{b}^{\mathrm{NC}}$ and thus for all $V$.

We now turn to the proof of the theorem. The post-conversion (PC) firm and the noconversion (NC) firm have only straight debt, but the NC firm has more debt, so $V_{b}^{\mathrm{PC}} \leq V_{b}^{\mathrm{NC}}$, and the inequality is strict if $P_{2}>0$. (If $P_{2}=0$, the result holds trivially.) We distinguish three cases based on the position of the conversion trigger relative to these default barriers.

Case 1: $V_{b}^{\mathrm{PC}} \leq V_{c} \leq V_{b}^{\mathrm{NC}}$. For all barrier choices $V_{b}$ with $V_{b} \leq V_{c}$, conversion precedes default, ${ }^{7}$ and the only choice among those that satisfies the commitment condition is $V_{b}^{\mathrm{PC}}$. For all feasible barrier choices $V_{b} \geq V_{c}$, default precedes conversion, so $E^{\mathrm{BC}}\left(V ; V_{b}\right)=E^{\mathrm{NC}}\left(V ; V_{b}\right)$, and the optimal choice among such barriers is $V_{b}^{\mathrm{NC}}$. Thus, these are the only two candidates for the optimal barrier level. If $V_{b}^{\mathrm{PC}}$ is consistent with limited liability for the BC firm, then Lemma 1 implies that $E^{\mathrm{BC}}\left(V ; V_{b}^{\mathrm{PC}}\right) \geq E^{\mathrm{NC}}\left(V ; V_{b}^{\mathrm{NC}}\right) \equiv E^{\mathrm{BC}}\left(V ; V_{b}^{\mathrm{NC}}\right)$, for all $V$. Thus, $V_{b}^{*}=V_{b}^{\mathrm{PC}}$ if $V_{b}^{\mathrm{PC}}$ is feasible, and otherwise $V_{b}^{*}=V_{b}^{\mathrm{NC}}$.

Case 2: $V_{c}<V_{b}^{\mathrm{PC}}$. For $V_{b}<V_{b}^{\mathrm{PC}}$, it follows from Chen and Kou [7] that the equity valuation $V \mapsto E^{\mathrm{PC}}\left(V ; V_{b}\right)$ violates limited liability, so no $V_{b} \leq V_{c}$ is feasible in this case. For all $V_{b}>V_{c}$, we have $E^{\mathrm{BC}}\left(V ; V_{b}\right) \equiv E^{\mathrm{NC}}\left(V ; V_{b}\right)$, so the optimal choice is $V_{b}^{\mathrm{NC}}$.

Case 3: $V_{b}^{\mathrm{NC}}<V_{c}$. If default precedes conversion, equity value is given by $E^{\mathrm{NC}}\left(V ; V_{b}\right)$. For each $V$, this is a decreasing function of $V_{b}$ for $V_{b} \geq V_{b}^{\mathrm{NC}}$; thus, no $V_{b}>V_{c}$ can be optimal. Among barriers $V_{b} \leq V_{c}$ for which conversion precedes default, only $V_{b}^{\mathrm{PC}}$ satisfies the commitment condition. Thus, we need to compare the default barriers $V_{b}^{\mathrm{PC}}$ and $V_{c}$, with default preceding conversion in the latter case. The argument in Lemma 1 now applies directly, replacing $\tau_{b}^{\mathrm{NC}}$ with $\tau_{c}$, and shows that $E^{\mathrm{BC}}\left(V ; V_{b}^{\mathrm{PC}}\right) \geq E^{\mathrm{NC}}\left(V ; V_{c}\right)$, for all $V>V_{c}$. The inequality is strict at $V=V_{c}$, so the optimal barrier is $V_{b}^{\mathrm{PC}}$.

\section{A.3 Proof of Theorem 2}

Set $\bar{P}_{1}=V_{c} / \epsilon_{1}$. If $P_{2}=0$ (so that the firm has only straight debt), then the optimal default barrier is $V_{b}^{*}=P_{1} \epsilon_{1}$. Thus, $V_{b}^{*} \leq V_{c}$ if $P_{1} \leq \bar{P}_{1}$, and $V_{b}^{*}>V_{c}$ if $P_{1}>\bar{P}_{1}$, which confirms that $\bar{P}_{1}$ is indeed the critical debt level in the absence of CoCos.

Now suppose $P_{1}<\bar{P}_{1}$ and $P_{2}>0$. From Theorem 1, we know that debt-induced collapse occurs when setting the default barrier at $V_{b}^{\mathrm{PC}}$ is infeasible because it violates limited liability;

\footnotetext{
${ }^{7}$ Recall our convention that when we write $V_{b} \leq V_{c}$, the order of events at $V_{b}=V_{c}$ is taken to be consistent with $V_{b}<V_{c}$, and when we write $V_{b} \geq V_{c}$ the opposite order of events is assumed.
} 
that is, when $E^{\mathrm{BC}}\left(V ; V_{b}^{\mathrm{PC}}\right)<0$ for some $V>V_{c}$. For any $V>V_{c}$, we have

$$
E^{\mathrm{BC}}\left(V ; V_{b}^{\mathrm{PC}}\right)=E^{\mathrm{PC}}\left(V ; V_{b}^{\mathrm{PC}}\right)+P_{2} A-P_{2} B-\frac{\Delta P_{2}}{1+\Delta P_{2}} M
$$

where

$$
A=\kappa \frac{c_{2}}{r} \mathbb{E}^{\mathrm{Q}}\left[1-e^{-r \tau_{c}}\right], \quad B=\left(\frac{c_{2}+m}{m+r}\right) \mathbb{E}^{\mathrm{Q}}\left[1-e^{-(r+m) \tau_{c}}\right]
$$

and

$$
M=\mathbb{E}^{\mathrm{Q}}\left[e^{-(r+m) \tau_{c}} E^{\mathrm{PC}}\left(V_{\tau_{c}} ; V_{b}^{\mathrm{PC}}\right)\right] \geq 0 .
$$

Here, $A$ gives the normalized value of the tax benefits from CoCos, and $B$ is the normalized value of the coupons and principal for the CoCos. Each of these (and $M$ ) is a function of the current asset level $V$, though we suppress this dependence in the notation.

Suppose $A<B$. This means that the tax benefit received is less than the value of the payments made on the debt, as we would expect in practice. In this case, the right side of (A.5) is decreasing continuously and without bound as $P_{2}$ increases. We may therefore define $\bar{P}_{2}^{V}$ to be the smallest $P_{2}$ at which (A.5) equals zero and then set

$$
\bar{P}_{2}=\inf \left\{\bar{P}_{2}^{V}: V>V_{c}\right\}
$$

If $P_{2}>\bar{P}_{2}$, then $P_{2}>\bar{P}_{2}^{V}$ for some $V>V_{c}$, and then $E^{\mathrm{BC}}\left(V ; V_{b}^{\mathrm{PC}}\right)<0$ for some $V>V_{c}$, so limited liability fails, $V_{b}^{\mathrm{PC}}$ is infeasible, and we have debt-induced collapse. If $P_{2} \leq \bar{P}_{2}$, then $P_{2} \leq \bar{P}_{2}^{V}$ for all $V>V_{c}$ and $E^{\mathrm{BC}}\left(V ; V_{b}^{\mathrm{PC}}\right) \geq 0$, so $V_{b}^{\mathrm{PC}}$ is feasible and then optimal.

For the alternative case $A \leq B$, it is not hard to see that $E^{\mathrm{PC}}\left(V ; V_{b}^{\mathrm{PC}}\right) \geq M$, so (A.5) remains positive at all $P_{2} \geq 0$, and the result holds with $\bar{P}_{2}=\infty$.

\section{B The Extended Model}

The extended model used in the numerical illustrations of Sections 5-8 extends (2.1) and (2.2) to allow two types of jumps - firm-specific jumps and market-wide jumps, with respective arrival rates $\lambda_{f}$ and $\lambda_{m}$, and mean jump sizes $\eta_{f}$ and $\eta_{m}$. In both cases, the jump sizes are exponentially distributed and decrease asset value. The extended model also allows more layers of debt: deposits (with or without insurance), ordinary debt, subordinated debt, and CoCos, in decreasing seniority. The multiple layers can be valued using the approach in Section 2.3. All parts of the capital structure can be valued in terms of transforms of $\tau_{b}$ and $\tau_{c}$, and these transforms can be expressed in terms of roots of an equation; see Chen et al. [6] for details. Table 5 shows parameter values for the numerical examples. The subscripts $1 a, 1 b$, and $1 c$ distinguish the three layers of non-convertible debt. 


\begin{tabular}{lr|l} 
Parameter & $V_{0}$ & 100 \\
\hline initial asset value & $\left(P_{1 a}, P_{1 b}, P_{1 c}\right)$ & $(40,30,15)$ \\
debt principal & $r$ & $6 \%$ \\
risk free rate & $\sigma$ & $8 \%$ \\
volatility & $\delta$ & $1 \%$ \\
payout rate & $\kappa$ & $35 \%$ \\
tax rate & $\lambda_{f}$ & .2 \\
firm specific jump intensity & $\lambda_{m}$ & .05 \\
market jump intensity & $\eta_{f}$ & 4 \\
firm specific jump exponent & $\eta_{m}$ & 3 \\
market jump exponent & $\left(c_{1 a}, c_{1 b}, c_{1 c}, c_{2}\right)$ & $(r, r+3 \%, r+3 \%, r)$ \\
coupon rates & $\varphi$ & $1 \%$ \\
deposits insurance premium rate & $P_{2}$ & 1 or 5 \\
contingent capital principal & $\left(m_{1 a}, m_{1 b}, m_{1 c}, m_{2}\right)$ & $(1,1 / 4,1 / 4,1 / 4)$ \\
maturity profile exponent - base case & $\left(m_{1 a}, m_{1 b}, m_{1 c}, m_{2}\right)$ & $(1,1 / 16,1 / 16,1 / 16)$ \\
maturity profile exponent - long maturity & & or $(1,1 / 25,1 / 25,1 / 25)$ \\
& $V_{c}$ & $75($ in most cases $)$ \\
conversion trigger & $20 \%$ of value of shares \\
conversion loss (if applied) & & \\
\hline
\end{tabular}

Table 5: Parameters for extended model. Asset returns have a total volatility (combining jumps and diffusion) of $20.6 \%$ and overall drift rate of $3.3 \%$. In the base case, the number of shares $\Delta$ issued at conversion is set such that if conversion happens at exactly $V_{c}$, the market value of shares delivered is the same as the face value of the converted debt. 